\title{
Educación LGB+. El derecho fundamental a educación básica contra la discriminación por orientación sexual(*)
}

\author{
$L G B+$ Education. The fundamental right to a basic education against \\ discrimination based on sexual orientation
}

Bruno Doig Gonzales Otoya ${ }^{(*)}$

Perú - Bullard Falla Ezcurra +

Resumen: El presente artículo justifica la existencia de un derecho fundamental a una escuela en la que se aborde y se busque erradicar la discriminación por orientación sexual. Para ello, se presentan argumentos en base al texto de la Constitución, jurisprudencia y el razonamiento moral. Específicamente, la hipótesis se basa en el derecho a la igualdad y el derecho a la educación, ya reconocidos por la práctica constitucional. Luego, se presentan diversas medidas para implementar dicho derecho en la realidad. Finalmente, el planteamiento se contrasta con los cuestionamientos vinculados a la potestad de los padres de guiar la educación de los hijos, la cual se basa en los principios de pluralismo y neutralidad del Estado.

Palabras clave: Orientación sexual - Derecho a la Educación - Derecho a la Igualdad - Discriminación - LGBT - Esencialismo - Construccionismo - Con mis hijos no te metas - Derechos Fundamentales

\begin{abstract}
The present paper justifies the existence of a fundamental right to an education that addresses and seeks to eradicate discrimination based on sexual orientation. To this end, the justification relies on the text of the Constitution, judicial precedents, and moral reasons. Specifically, the hypothesis is based on the right to equality and the right to education, widely recognized by the constitutional practice. Thereafter, the means of implementation for the said right are presented. Finally, the argument is confronted with the critics related to the power of the parents to guide the education of their children, which is based on the principles of pluralism and state neutrality.
\end{abstract}

Keywords: Sexual Orientation - Right to Education - Right to Equality - Discrimination LGBT - Essentialism - Constructionism - Con mis hijos no te metas - Fundamental Rights

$\left(^{*}\right) \quad$ Nota del Editor: el artículo fue recibido 15 de octubre de 2019 y su publicación fue aprobada el 5 de noviembre de 2019.

${ }^{* *}$ Abogado por la Pontificia Universidad Católica del Perú. Estudios de Derecho en la Freie Universität Berlin. Especialización en Derecho internacional Público y Privado por la Academia de Derecho Internacional de La Haya. Asociado en Bullard Falla Ezcurra. Correo electrónico: bdoig@bullardabogados.pe 
Educación LGB+. El derecho fundamental a educación básica contra la discriminación por orientación sexual

LGB+ Education. The fundamental right to a basic education against discrimination based on sexual orientation

\section{Introducción}

Sergio Urrego Reyes tenía 16 años cuando decidió quitarse la vida un 4 de agosto de 2014 en la ciudad de Bogotá, Colombia. Sergio iba al colegio como cualquier niño de su edad. Su madre refirió que "era un joven brillante, excelente ser humano, devorador de libros y preocupado por las problemáticas sociales y el medio ambiente" (Corte Constitucional de Colombia, 2015, pág. 1). Como cualquier niño de su edad, Sergio estaba enamorado. La diferencia es que Sergio estaba enamorado de un muchacho. Era homosexual.

Por ser homosexual, el colegio era particularmente duro para él. Era un infierno. Afrontaba diariamente el acoso de sus compañeros. En lugar de encontrar comprensión y protección en los docentes, encontraba rechazo. Para todos los demás, Sergio era un enfermo, un inmoral, una falla de la naturaleza. Sergio solo podía ver el colegio como un preludio a un futuro peor. Luego de que se descubra la relación homosexual que mantuvo con Horacio, su compañero de clase y novio, sufrió denuncias de acoso por los padres de este último, el escarnio de su círculo de pares, procesos disciplinarios iniciados por el colegio y la obligación de acudir al psicólogo para tratar su problema. Sergio no pudo soportarlo y decidió quitarse la vida.

El caso llegó a la Corte Constitucional de Colombia. Su madre solicitó el desagravio público por parte de la institución educativa. La Corte encontró que la escuela y el Estado habían fallado en proveer protección a Sergio y a todos los niños que afrontan acoso por su identidad sexual. Por ello, ordenó directamente al Ministerio de Educación "implementar, si no lo ha hecho aún, al programa para el desarrollo de competencias ciudadanas, la educación para el ejercicio de los derechos humanos (en particular el derecho a la identidad sexual) e incorporarlos de manera expresa en los proyectos educativos institucionales de todos los colegios del país" (Corte Constitucional de Colombia, 2014, Tercero), entre otras medidas tendientes a proteger a la niñez LGB y desagraviar la imagen de Sergio.

El caso de Sergio es quizás el más trágico, pero es solo uno de los síntomas que atraviesa la sociedad actual y, por supuesto, el Perú. Los niños que no se adecúan a las normas de género o que empiezan a descubrir su atracción por otros niños del mismo sexo deben afrontar la burla de sus compañeros, la desprotección de sus profesores y autoridades educativas y, muchos aún, el desamparo de su familia.

Los estudios actuales revelan que existe una prevalencia de problemas emocionales, psicológicos y violencia física en niños LGB derivados del ambiente escolar, al igual que graves problemas de aprendizaje. Estos niños crecerán también para sufrir la homofobia de la sociedad. Lo cierto es que, la escuela, que es financiada por los contribuyentes para buscar una sociedad más justa, debería estar llamada a proteger a los niños LGB. Pero actualmente se ha avanzado poco. $Y$ lo poco que se ha avanzado ha generado oposición de diversos sectores conservadores de la sociedad. El currículo educativo peruano actual ha sobrevivido a un proceso judicial que podría haber desarticulado los primeros pasos a una mayor protección de los derechos de los niños de orientación sexual diversa (Corte Suprema del Perú, 2018-2019).

Sin embargo, la decisión de la Corte Suprema es aún parca respecto a la orientación sexual y respecto a la relación jurídica que tiene el Estado en ese respecto. Esto es, queda aún abierta y necesaria la discusión en el ámbito académico de si el Estado se encuentra legitimado para brindar educación en la que se aborde directamente temática sobre orientación sexual y se enseñe a los niños a no discriminar por tal motivo. Más aún, queda abierta la cuestión de si no existe más bien un derecho fundamental en ese sentido.

Los derechos fundamentales precisamente se tratan de aquellos espacios de protección de los seres humanos sobre los cuales no puede decidir nadie más, ni siquiera la mayoría política. En base a esta consideración, en este artículo se busca responder a la pregunta de si los niños homosexuales, bisexuales y, en general, de orientación sexual no-normativa tienen un derecho a una escuela que los proteja de la discriminación. La posición que se defiende es que, en efecto, es así.

Para contestar a dicha pregunta, en (2) se busca comprender qué es la orientación sexual, a partir de la distinción entre los enfoques esencialista y constructivista, y particularmente cómo se manifiesta la diversidad de orientación sexual en los niños, los principales beneficiarios de la educación. En (3) se busca justificar la existencia de un derecho fundamental en base al derecho a la igualdad y el derecho a la educación, desde una perspectiva del constitucionalismo contemporáneo de los derechos y sosteniéndose en un discurso construido a partir de la interpretación del texto constitucional, los precedentes del Tribunal Constitucional peruano y las cortes internacionales de derechos humanos; así 
como a partir del razonamiento moral. Finalmente, en (4) se contestan los argumentos que niegan la constitucionalidad de que el Estado implemente una política de igualdad de género en la educación peruana, los cuales se han vinculado en los últimos años al movimiento "Con mis hijos no te metas". En (5) se identifican las principales conclusiones.

\section{2. ¿Qué es la orientación sexual?}

\subsection{Enfoque esencialista y enfoque constructivista}

Existen miles de estudios sobre la orientación sexual. Como no podemos detenernos en todos, es necesario buscar una clasificación que nos permita entender las principales ideas que rodean el concepto. Los dos grandes enfoques son el esencialismo y el construccionismo.

El esencialismo propone que la orientación sexual es un concepto impermeable a la historia y a la cultura y, por tanto, será el mismo en cualquier tiempo y lugar. A este concepto suele asociarse la idea de que la orientación viene con el nacimiento (Bamforth, 1997, pág. 76) Por ejemplo, un esencialista propondría que las características de un homosexual en la Grecia antigua son las mismas que las de un homosexual en Nueva York de 1968 y un homosexual del Magdalena del Mar en 2019.

En el siglo $\mathrm{XXI}$, diversos estudios científicos orientados a buscar la causa de la orientación sexual son considerados dentro del paradigma esencialista. Las dos teorías que gozan de mayor aceptación en la comunidad científica son: (i) el nivel de exposición del feto a las hormonas andrógenos que, de acuerdo a dichos estudios, son las que masculinizan las características anatómicas y neuroanatómicas del feto, (Dawood, Bailey \& Martin, 2009, pág. 275-276); y (ii) en el caso de hombres, la menor exposición del feto al antígeno $\mathrm{H}-\mathrm{Y}$ del vientre materno por haber concebido a otros hijos hombres previamente, lo cual vincularía el orden de nacimiento con la probabilidad de ser homosexual (Dawood, Bailey y Martin, 2009, pág. 276-277).

El construccionismo, por el contrario, propone que la experiencia de la orientación sexual se interrelaciona y retroalimenta de la cultura, la política y la economía (Rubin,1975, pág. 166). Algunos asocian esta concepción con la idea de que la orientación sexual es fluida y maleable a lo largo de la vida de las personas. Entonces, a este concepto suelen asociarse teorías que consideran que la homosexualidad es adquirida durante el desarrollo (Bamforth, 1997, pág. 76).

Por ejemplo, Michel Foucault discutió cómo las instituciones morales y jurídicas victorianas, represivas de la sexualidad, antes que contribuir a limitar expresiones sexuales, ayudaron a construir el concepto de un sujeto "homosexual". Antes se hablaba de prácticas contra natura; pero, a partir del siglo XIX ya se habla del homosexual. Se muestra así, cómo la política, la cultura y la economía moldean la identidad sexual (Foucault, 2012, pág. 7-9, 27-28). Judith Butler (1990), en otro ejemplo, propone que el género, se va construyendo con las acciones diarias, como una performance en la sociedad. Además, cuestiona si es posible establecer una dicotomía entre la cultura y el cuerpo, pues propone que el entendimiento del cuerpo y lo biológico no puede desligarse tampoco de la cultura, la política y la economía.

Este texto propone que para entender la orientación sexual no basta ni es suficiente ninguna de dichas aproximaciones. Las mismas no son necesariamente contradictorias, sino que abordan distintos aspectos de la sexualidad (Fausto-Sterling, 2000). La ciencia necesita delimitar conceptos y variables para poder establecer correlaciones y proponer relaciones de causa y efecto estadísticamente comprobables. Sin embargo, la academia no debe perder de vista la instrumentalidad de los conceptos y la necesidad de entender los límites culturales y éticos de cada teoría y de cada estudio. Asimismo, la sexualidad rebasa lo biológico y lo aprehensible por el método científico. En algunas ocasiones, una pintura abstracta quizás pueda hablarnos más sobre la sexualidad que una prueba de laboratorio.

\subsection{Diversidad sexual y de género}

En base a las concepciones indicadas, en la actualidad, podemos hablar de por lo menos cuatro aspectos centrales para la comprensión y tratamiento legal de la orientación sexual: el sexo, el género, la identidad de género y la orientación sexual.

El sexo refiere al conjunto de características del cuerpo humano vinculadas a la reproducción y en función de las cuales es posible categorizar a las personas. Para ello, existen una serie de indicadores como "los cromosomas sexuales, las gónadas, los órganos reproductores internos y los genitales". Ello permite clasificar a las personas como de sexo masculino, sexo femenino o intersexuales (American Psychological Association, 2012, pág. 11; Comisión Interamericana de Derechos Humanos, 2012, pág. 13).

El género se refiere a las "actitudes, pensamientos y comportamientos que una cultura asocia con el sexo biológico de una 
Educación LGB+. El derecho fundamental a educación básica contra la discriminación por orientación sexual

LGB+ Education. The fundamental right to a basic education against discrimination based on sexual orientation

persona" (American Psychological Association, 2012, pág. 11). Es decir, la cultura relaciona ciertas formas de ser, de verse, de comportarse, de pensar y de sentir al hecho de pertenecer a un sexo o al otro.

Usualmente se equipara la dualidad sexo/género con la dualidad biología/cultura (Comisión Interamericana de Derechos Humanos, 2012). No obstante, a partir de las críticas de Fausto-Sterling (2000) y de Judith Butler (1990), se ha resaltado el problema que conlleva esta aparente dualidad. El reconocimiento de una esfera biológica, desde la cual es posible clasificar a las personas, podría llevar al olvido de que las categorías son simplemente construcciones lingüísticas con el propósito de simplificar la realidad para entenderla, llevando en algunos casos a la imposición de ese ideal. Así, por ejemplo, personas intersexuales son forzadas quirúrgicamente a amoldarse al ideal de hombre/mujer, pensando que ese es el mandato de la naturaleza.

La identidad de género hace referencia a la "profundamente sentida experiencia interna e individual del género, que puede o no corresponderse con el sexo asignado en el nacimiento" (International Commission of Jurists, 2007). En otras palabras, el concepto de pertenencia que tiene cada persona a una categoría de género, sea normativa, disidente, con elementos variados o a ninguna categoría de género.

En lo que sigue del presente texto, nos concentraremos en la orientación sexual. La orientación sexual hace referencia a la capacidad de la persona de sentirse profundamente atraída sexual y/o románticamente hacia personas de determinado sexo o de determinado género (International Commission of Jurists, 2007).

Si bien usualmente se clasifica a las personas en homosexuales, heterosexuales y bisexuales, ello es discutible. En un estudio muy temprano, el Prof. Kinsey (1993) prefirió referirse a la orientación sexual como un continuum en el que existen diferentes grados de atracción por uno u otro sexo. Asimismo, cabe destacar que la orientación sexual para muchas personas no es fija e invariable, sino continuamente fluida (Comisión Interamericana de Derechos Humanos, 2012).

Las personas que prefieren mantenerse en la indefinición de la orientación sexual, asumir la fluidez y restarle importancia al sexo o género en el amor por otra persona, prefieren denominarse como "pansexuales", aludiendo a la atracción por cualquier persona, independientemente de su sexo, o identidad de género. En el mismo sentido también se utiliza el término queer ("rarito"), aludiendo a la indefinición en cuanto a la orientación sexual. Asimismo, se ha destacado también la existencia de personas "asexuales", en la medida que no sienten atracción sexual por otras personas (Comisión Interamericana de Derechos Humanos, 2012).

\section{3. ¿Patología o diversidad?}

Actualmente el consenso médico internacional no considera a la homosexualidad como una enfermedad. El Diagnostic and Statistical Manual of Mental Disorders (DSM) III de la American Psychiatric Association fue el primer manual en retirar la homosexualidad del diagnóstico de enfermedades en 1973, sentando un importante hito en los derechos LGB. De forma algo más tardía, la Clasificación Internacional de Enfermedades (CIE), publicado por la OMS, retiró la homosexualidad de su clasificación en 1990 (Drescher, 2015).

La homosexualidad no genera directamente malestar ni menoscabo al desenvolvimiento social de la persona. Los estudios actuales han demostrado que no existe diferencia en razón de la orientación sexual entre personas homosexuales y personas heterosexuales en cuanto al bienestar psicológico y autoestima. Tampoco existe diferencia entre ambos grupos con respecto a las habilidades cognitivas. Tampoco existe evidencia de correlación necesaria con enfermedades mentales (American Psychological Association, 2012).

Sin embargo, un mayor grupo de personas homosexuales tienen propensión a la ansiedad, depresión, el abuso de drogas y el suicidio. Los adolescentes se encuentran en mayor riesgo. Los estudios actuales atribuyen dichos trastornos psicológicos a los efectos del estrés relacionado con la estigmatización y discriminación o minority stress en inglés. Dichas diferencias serían consistentes con los estudios sobre el estrés causado por la exposición a comportamientos discriminatorios, por ejemplo, por motivos de etnia (Roberts, 2010; Cochran, 2001; Hatzenbuehler, 2009).

Algunos estudios también han demostrado que las terapias reparativas para el cambio de la orientación sexual son mayoritariamente ineficaces y generan un alto costo psicológico para las personas que las atraviesan. La American Psychological Association (2012) señala que dicho tipo de terapias "no puede ser recomendado como un tratamiento efectivo" y que "los beneficios reportados por los participantes en esfuerzos de cambio en 
la orientación sexual pueden ser obtenidos por aproximaciones que no intenten cambiar la orientación sexual". Sin embargo, los estudios científicos aún no son concluyentes al respecto (Zucker, 2003; Spitzer, 2003). En cualquier caso, la orientación sexual es una experiencia íntima que no debe estar sujeta a la intervención de un tercero.

En síntesis, al igual que hay personas altas y bajas, de piel oscura y piel clara, la homosexualidad es también una variación normal de la personalidad. No cabe hablar de una patología en tanto, per se, no se trata de una afectación al desenvolvimiento normal de la persona. Lo que causa el sufrimiento de las personas LGB es en realidad la homofobia.

\subsection{Desarrollo humano y orientación sexual. ¿Podemos hablar de niños homosexuales?}

Si bien en principio las fases de desarrollo de la sexualidad tienden a coincidir entre personas heterosexuales y noheterosexuales, la heteronormatividad de la sociedad causa determinadas particularidades con respecto a las personas noheterosexuales. Los estudiosos del desarrollo y la orientación sexual identifican hitos en la vida de las personas con relación a su orientación sexual: la identificación de la atracción por personas del mismo sexo, etapa de confusión por la sexualidad, autoidentificación, revelación de la sexualidad al entorno e iniciación de relaciones sexuales con personas del mismo sexo (D'Augelli, 1994; Calzo et al, 2011; Floyd y Stein, 2002).

Durante la infancia, hasta alrededor de los 12-14 años, los niños no tienden a sentir atracción sexual. Sin embargo, muchos niños que se convertirán en adultos homosexuales tienen expresiones de género distintas. Hablamos de niños que son considerados afeminados y niñas que son consideradas masculinas. Por supuesto, no todos los niños con expresiones de género no-normativas se identificarán luego como homosexuales, ni transgénero; algunos luego serán personas que se identificarán como cisgénero y heterosexuales (Zucker, 2008).

A partir de la pubertad, entre los 12-14 años, los niños/ adolescentes empiezan a sentir atracción sexual y en eso la estadística demuestra que los niños heterosexuales y no-heterosexuales tienden a coincidir. Sin embargo, en la medida que la sociedad asume que todas las personas son heterosexuales, los niños/adolescentes no-heterosexuales tienden a atravesar un periodo de confusión, lucha interna y un final descubrimiento y asunción de su identidad como personas no-heterosexuales. Finalmente, existe un proceso de revelación a las personas del entorno amical, familiar e inclusive laboral respecto a la orientación sexual. Esto es, el proceso denominado "salir del closet" (D'Augelli, 1994; Calzo et al, 2011; Floyd y Stein, 2002, Perez-Wicht Arispe, 2017).

Como se indicó, el proceso no es uniforme y varía en cada persona dependiendo de múltiples factores. El estigma del entorno respecto a la orientación sexual puede llevar a que muchas personas no descubran, asuman o revelen nunca, o hasta una edad avanzada, su sexualidad. Asimismo, considerando la fluidez de la bisexualidad, los estudios tienden a tener dificultades para medirla (Rivers, 1997).

Lo relevante es que desde el comienzo de la edad escolar existirán niños diferentes. En la primera infancia es usual la expresión de género diversa. En la pubertad, en los años de secundaria, los niños/adolescentes empezarán a sentir atracción sexual por personas de su mismo sexo o género y ello conlleva distintos procesos de confusión, descubrimiento y asunción de la identidad sexual. Este proceso, en el marco de una sociedad heteronormativa y homofóbica, pone a los niños LGB en una situación de vulnerabilidad frente a distintos problemas de salud psicológica y física.

Es por ello, que resulta esencial que empecemos a hablar del derecho fundamental que tienen los niños a que la escuela los proteja de la discriminación. En el siguiente acápite analizamos cómo tal discurso es posible.

\section{Derecho a una escuela que erradique la disc riminación por orientación sexual}

En el presente acápite abordamos el problema producido por la homofobia en la escuela. A partir del mismo, se sostiene que, para afrontarlo, resulta posible sostener la existencia de un derecho a una educación escolar que aborde y busque erradicar la discriminación por orientación sexual.

En la línea del constitucionalismo de los derechos, se argumenta que dicha posición evolucionista se basa en el texto constitucional, la jurisprudencia y los argumentos prácticos (Alexy, 1993, pág. 533) que soportan tanto el derecho a la no-discriminación como el derecho a la educación, cuyo reconocimiento ya se encuentra asentado en la práctica legal. En base a los mismos, sostenemos que es posible deducir la necesidad de que la educación proteja a los niños de la discriminación por orientación sexual. Ello representa un mandato directo en las políticas públicas estatales, pues los derechos 
Educación LGB+. El derecho fundamental a educación básica contra la discriminación por orientación sexual

LGB+ Education. The fundamental right to a basic education against discrimination based on sexual orientation

fundamentales son aquellos que no pueden ser menoscabados por la mayoría (Alexy, 2006, pág. 15).

\subsection{La homofobia en la escuela}

Como demuestra la historia de Sergio Urrego, la homofobia arraigada en la sociedad se manifiesta también en la escuela. La escuela actual es un foco desde el cual se produce y se reproduce la homofobia. Para entender esta situación, podemos aproximarnos desde dos perspectivas: una individual y una colectiva. Primero, la homofobia escolar causa directamente que los niños sufran daños físicos, daños psicológicos y problemas de aprendizaje que truncan su futuro. Segundo, la homofobia escolar causa indirectamente la reproducción de la homofobia en la sociedad.

Primero, en la escuela existe una prevalencia del acoso escolar homofóbico contra los niños no heterosexuales o que son percibidos como tales (UNESCO 2013; UNESCO 2015). El Dr. Cáceres (2013), en un reciente estudio encargado por la UNESCO en escuelas de Perú, Guatemala y Chile, reveló una mayor incidencia de acoso escolar en los niños y adolescentes no-heterosexuales en las escuelas peruanas objeto de estudio, pues un $68 \%$ de sujetos que declararon pertenecer a dicha categoría reportó haber sido objeto de bullying en la escuela por parte de alguien, frente al $43 \%$ de heterosexuales que lo reportaron (pág. 16). La estadística se repite en un estudio nacional de PROMSEX en 2016, en el cual se reportó que el $70.1 \%$ de estudiantes homosexuales y bisexuales se sintieron inseguros el año anterior en el colegio (pág. 23).

Algunos estudios apuntan, además, a que el acoso escolar homofóbico tiene incidencias más graves que el acoso escolar por otros motivos. Por ejemplo, un estudio descubrió que las víctimas de acoso escolar homofóbico tenían 5.82 veces más probabilidades de tener ideas suicidas que los niños que no sufrían acoso; mientras que las víctimas de otro tipo de acoso escolar, e.g. étnico, eran 2.86 más propensos a las ideas suicidas (Poteat, 2017, pág 29).

El acoso escolar homofóbico tiene una serie de efectos negativos en los niños y adolescentes afectados, así como en el ambiente escolar en general. Diversos estudios han demostrado la incidencia de dicho problema en trastornos psicológicos como la depresión, ansiedad generalizada, inseguridad, insomnio, estrés post traumático, abuso de drogas e, incluso, suicidio. El acoso escolar homofóbico perjudica el aprendizaje de las víctimas, disminuyendo los logros y el rendimiento académico y, asimismo, provoca el ausentismo e, incluso, la deserción escolar temprana. Estos problemas se asocian con el estrés de minoría (minority stress) que es una constante también en las personas adultas con orientación sexual disidente (American Psychological Association, 2015; American Psychological Association, 2012; UNESCO, 2013; UNESCO, 2015; Poteat, 2017, pág. 27-30).
La discriminación en general desde la educación, y particularmente el currículo, ha venido siendo investigada por los estudios de la mujer y los estudios afroamericanos desde la década de 1970. Estas aproximaciones revelaron que desde la organización de las materias hasta las ilustraciones y ejemplos de los libros de texto estaban dominados por hombres blancos y distorsionaban o disminuían las vidas de las mujeres y de las personas afroamericanas. Entre la década de 1970 y 1980, se midieron los resultados de un currículo revisado para reflejar adecuadamente la diversidad de género y raza. Los estudios revelaron que existía una mejora en la relación entre los grupos no-dominantes y los grupos hegemónicos, demostrando mejores resultados académicos, mejores actitudes y reducción de los estereotipos (American Association of University Women, 2017, pág. 205-206).

Estas investigaciones dieron lugar a la teoría de la educación multicultural, un paradigma actual que estudia las respuestas desde la escuela a la discriminación de los grupos minoritarios: grupos de género, étnicos, religiosos, identidades sexuales e incluso los niños excepcionales. La educación multicultural parte del presupuesto de que el sistema educativo está construido únicamente de cara a las necesidades y formas de aprendizaje del grupo cultural dominante de la sociedad, lo cual priva a los niños de grupos minoritarios de las mismas oportunidades de aprendizaje y permite la reproducción de la discriminación y la construcción de prejuicios (Banks, 2013, pág. 1-21).

Una escuela que no representa y que no se adapta a las particularidades de cada grupo social es una escuela que no brindará las mismas oportunidades de aprendizaje a dichos niños. La UNESCO ha reconocido que una educación de calidad debe incluir, representar y adaptarse a las necesidades de aprendizaje y las necesidades de contenido relevante para cada niño (Stabback, 2016, pág. 18). De lo contrario, la escuela puede convertirse en un instrumento de violencia homofóbica implícita e institucional (UNESCO, 2016, pág. 26). 
El tratamiento de la discriminación desde la educación multicultural parte de las teorías de psicología social del contacto intergrupal de Gordon Allport, sobre la base de la teoría del aprendizaje social de Albert Bandura. Bajo la hipótesis del Dr. Allport, la falta de contacto entre grupos sociales bajo ciertas condiciones alimenta el prejuicio, la discriminación y el rechazo entre ellos. De acuerdo con ello, un currículo que omite o perpetúa prejuicios respecto de grupos minoritarios es un factor que permite la reproducción de los prejuicios (Banks, 2013, pág. 17-18; Leby et al, 2016, pág. 455-477; Pettigrew, 1998). Siguiendo la teoría del contacto extendido, el contacto puede producirse mediante el aprendizaje sobre otros grupos o la lectura de contactos del grupo al que pertenece con otros grupos y mediante la imaginación del contacto (Levy et al, 2016, pág. 467-468).

De acuerdo con lo señalado, puede afirmarse que una escuela que priva de contacto e información a un grupo de niños respecto del grupo social al que pertenecen es discriminatoria por dos motivos: por un lado, los priva de las mismas oportunidades educativas y de aprendizaje; por otro lado, se trata de un factor que perpetua el prejuicio y la discriminación contra el grupo minoritario. Al respecto, resulta muy explicativa la metáfora del currículo como un espejo y una ventana planteada por la profesora Style. El currículo es un espejo para que los niños puedan aprender sobre sí mismos y una ventana para que puedan aprender sobre el otro. En ese sentido, una educación que no es inclusiva impide que los niños aprendan sobre sí mismos y aprendan sobre los grupos oprimidos (Style 1998).

Es por ello que diversos organismos internacionales y la academia han destacado la importancia de la educación, la divulgación de información, las políticas educativas, el papel de los maestros, el currículo y los contenidos de enseñanza sobre diversidad sexual en la erradicación de la discriminación por orientación sexual (Poteat, 2015, pág. 22-23; Alto Comisionado de las Naciones Unidas para los Derechos Humanos, 2005, pág. 57). El Relator de la ONU sobre el derecho a la educación ha destacado asimismo la corrección del principio 16 de los Principios de Yogyakarta (Relator Especial de las Naciones Unidas sobre el derecho a la educación, 2010, pág. 23; Comisión Interamericana de Derechos Humanos, 2015, pág. 248; Snapp y Russell, 2017, pág. 146), según el cual "everyone has the right to education, without discrimination on the basis of, and taking into account, their sexual orientation and gender identity"(1).

Segundo, desde un punto de vista colectivo, la educación se convierte además en un factor elemental para la reproducción de la discriminación, tanto porque priva de oportunidades de aprendizaje adecuadas a los grupos discriminados, como porque alimenta el rechazo de las personas del grupo dominante. La reproducción de los patrones, reglas e identidades de la sociedad y la cultura en la escuela es un asunto estudiado desde tiempos de Platón y Aristóteles (Collins, 2009, pág. 34) hasta la actualidad (Meyer, 2010, pág. 22). En el caso de la homofobia y heteronormatividad, el profesor Palmer (2017) es muy claro al señalar que "las escuelas producen y reproducen la heterosexualidad como la única opción 'normal' y viable (Kejily, 2002) mientras refuerzan simultáneamente normas rígidas de género que marginalizan a aquellos que no se conforman con el estricto sistema binario de género (Connel, 1996)" (pág 59). Este rol de la educación en la reproducción de los patrones heteronormativos y homofóbicos en el currículo ha sido destacado por la academia (Meyer, 2010, pág. 54-55).

Veamos entonces, cuáles son los argumentos para sostener que el Derecho Constitucional peruano reconoce un derecho a una educación que proteja a los niños de la discriminación.

\subsection{Derecho a la igualdad}

El principio de igualdad y la prohibición de discriminación se encuentran expresados en el artículo 2.2 de la Constitución, de acuerdo con el cual, "toda persona tiene derecho: (...) a la igualdad ante la ley. Nadie debe ser discriminado por motivo de origen, raza, sexo, idioma, religión, opinión, condición económica o de cualquiera otra índole".

(1) Los Estados deben:

"A. Take all necessary legislative, administrative and other measures to ensure equal access to education, and equal treatment of students, staff and teachers within the education system, without discrimination on the basis of sexual orientation or gender identity; B. Ensure that education is directed to the development of each student's personality, talents, and mental and physical abilities to their fullest potential, and responds to the needs of students of all sexual orientations and gender identities;

C. Ensure that education is directed to the development of respect for human rights, and of respect for each child's parents and family members, cultural identity, language and values, in a spirit of understanding, peace, tolerance and equality, taking into account and respecting diverse sexual orientations and gender identities; 
Educación LGB+. El derecho fundamental a educación básica contra la discriminación por orientación sexual

LGB+ Education. The fundamental right to a basic education against discrimination based on sexual orientation

La jurisprudencia del Tribunal Constitucional ha recogido formulaciones amplias del principio de igualdad, que sobrepasan al principio de igualdad formal(2). Actualmente, se busca que las personas gocen de las condiciones materiales que les permitan hacerse responsables de su propia vida. Estas formulaciones no solo son admisibles desde un punto de vista de interpretación teleológica y evolucionista del propio artículo 2.2 de la Constitución, sino que, desde un criterio de interpretación literal, forman parte de los principios constitucionales en virtud del artículo 3 , al ser principios "de naturaleza análoga o que se fundan en la dignidad del hombre".

La teoría política contemporánea, así como la jurisprudencia de derechos humanos en el mundo plantean la igualdad en sentido material, la desigualdad para desiguales y la discriminación indirecta como principios necesarios para el respeto de la dignidad de las personas. Una persona recibe el máximo respeto, y por tanto goza de dignidad humana, cuando tiene la posibilidad de llevar las riendas de su propia vida. Como señala Ronald Dworkin (2011), "People must be allowed responsibility for their own lives" (pág. 365). Cada persona tiene derecho a actuar conforme a sus propias decisiones y a percibir los beneficios o consecuencias negativas de sus propios actos.

La posición que une a las diversas variantes del liberalismo igualitarista precisamente sostiene que una sociedad es injusta cuando permite que las condiciones sociales o naturales sean las que determinen el destino de las personas antes que sus propias decisiones (Shapiro, 2007, pág. 21). No se trata de una sociedad en la que se pueda tomar decisiones, actuar conforme a las mismas y beneficiarse de las consecuencias o responder por ellas. Las condiciones de nacimiento son las que generan los beneficios o los perjuicios. No se trata de una sociedad en la que se respete la dignidad de los ciudadanos. Por tanto, el Estado debe buscar equiparar las condiciones de partida para que todas las personas tengan las mismas oportunidades para buscar la felicidad.

Entonces, existirá igualdad cuando las condiciones materiales de nacimiento no determinan el destino de una persona, sino sus propias decisiones. Teniendo en cuenta lo señalado, para determinar si en un caso concreto se vulnera el derecho a la igualdad y existe un caso de discriminación, se pueden plantear diferentes exámenes dependiendo de la situación:

a) El principio de igualdad formal tradicional es una prohibición de arbitrariedad en la formación y aplicación de las leyes
(Tribunal Constitucional del Perú, 28 de junio de 2004, pág. 10; 26 de marzo de 2003, párr. 3.2; 1 de abril de 2005; 16 de abril de 2014, párr. 5; 13 de diciembre de 2011, párr. 39). Como establece el artículo 103 de la Constitución, "Pueden expedirse leyes especiales porque así lo exige la naturaleza de las cosas, pero no por razón de las diferencias de las personas." Su planteamiento dio lugar al tradicional test de discriminación relacional por el cual se debe establecer (i) un parámetro de comparación para la víctima de discriminación, (ii) un trato menos favorable respecto al parámetro de comparación y (iii) la ausencia de justificación objetiva y razonable en base al test de ponderación (McCrudden, 2009, pág. 11; Rey Martínez, 2018, pág. 128-129; Fredman, 2011, pág. 4-5; Alexy, 1989, pág. 222-228).

b) La prohibición de discriminación por motivos prohibidos se origina en la necesidad de proteger a ciertas categorías de personas históricamente marginadas. La Constitución plantea un numerus apertus de categorías de personas. La demanda de discriminación por motivos prohibidos da lugar a una inversión de la carga de la prueba a favor de la víctima y da lugar a mayor peso al principio de igualdad en el test de ponderación (Tribunal Constitucional del Perú, 9 de diciembre de 2015, párr. 18; 3 de setiembre de 2010, párr. 34). La justificación debe tener razones muy poderosas para ser legítima.

c) La discriminación indirecta es una variación del test relacional de discriminación en los casos en que una medida, criterio o política neutral o igualitaria da lugar a un impacto perjudicial en un grupo o colectivo de personas (Fredman, 2011, pág. 177178; Corte Suprema de Estados Unidos, 8 de marzo de 1971; Comité de Derechos

(2) Debe notarse, no obstante, que, desde un punto de vista textual e histórico, el artículo 2.2 únicamente contendría la igualdad y no discriminación en sentido formal. Por ello, el texto solo menciona la "igualdad ante la ley". Además, el Congreso Constituyente decidió no aprobar la inclusión de una disposición expresa que incluya la igualdad material, propuesta por el profesor Henry Pease, constituyente, en el sentido de establecer que "el Estado promoverá las condiciones para que la igualdad sea real y efectiva, y adoptará medidas en favor de grupos discriminados o marginados" (Eguiguren, 1997, pág. 69). Es decir, desde una posición originalista, la intención de la mayoría fue establecer únicamente la igualdad en sentido formal en la Constitución de 1993 en el artículo 2.2 de la Constitución. 
Humanos de Naciones Unidas, 15 de junio de 2004, párr. 9.3; Comité de Derechos Humanos de Naciones Unidas, 22 de setiembre de 2003, párr. 10.2; Tribunal Constitucional del Perú, 6 de noviembre de 2008, párr. 54; 23 de diciembre de 2015, párr. 22).

d) La discriminación estructural se da en los casos en que está involucrado un grupo o categoría protegido de personas y no es posible establecer un parámetro de comparación. Se debe entonces prescindir de este último requisito para probar un caso de discriminación. Esta es una manifestación de la igualdad en sentido material, que incluso da lugar al mandato de realizar ajustes razonables o tomar acciones positivas con el objeto de lograr que las personas puedan lograr hacerse responsables de sus propias vidas y evitar las barreras impuestas por la sociedad (Fredman, 2011, pág. 168; Gavara de Cava, 2005, pág. 55; Tribunal Europeo de Justicia, 1990; 14 de julio de 1994; Tribunal Constitucional del Perú, 6 de noviembre de 2008; 23 de diciembre de 2015).

Teniendo en cuenta lo señalado, podemos afirmar que en base al derecho a la igualdad puede derivarse un derecho a una educación contra la discriminación por orientación sexual, basado en los supuestos d) y b). En el caso de la discriminación estructural, justificamos que los niños con orientación sexual diversa, o percibidos como tales, son un grupo protegido por ser históricamente segregados. Entonces, al ser la escuela un foco de producción y reproducción de dicha situación, el Estado debe intervenir. En el caso de la discriminación inversa, justificamos que una educación que omite la existencia de niños de sexualidad diversa afecta de forma negativa a dicho grupo protegido.

Primero, el consenso actual es que la orientación sexual es un motivo protegido frente a la discriminación, equiparable a la etnia, la religión o el sexo. La jurisprudencia nacional e internacional es unánime en considerar que la orientación sexual es un motivo prohibido de discriminación. El Comité Internacional de Derechos Humanos lo indicó en 1994 en la decisión del caso Toonen v. Australia (Comité de Derechos Humanos de las Naciones Unidas, 1994, párr. 8.7). Lo propio ha ocurrido con la Corte Interamericana de Derechos Humanos en el caso Atala Riffo v. Chile (Corte Interamericana de Derechos Humanos, 24 de febrero de 2012) y el Tribunal Europeo de Derechos Humanos en el caso Salgueiro da Mouta v. Portugal (Tribunal Europeo de Derechos Humanos, 21 de diciembre de 1999, párr 36; 22 de enero de 2008, párr. 91). El propio Tribunal Constitucional peruano ha señalado en obiter dictum que la orientación sexual es un motivo prohibido de discriminación en el caso Rosa Bethzabé Gambini Vidal (Tribunal Constitucional del Perú, 6 de noviembre de 2008, párr. 37).

De ello no debe quedar duda. Las personas noheterosexuales, o percibidas como tales, han sido sometidas históricamente a vejaciones y obstrucciones en su libertad y dignidad sin razón o justificación objetiva y razonable alguna. Este grupo ha sufrido y sufre de violencia de las leyes, de las autoridades y de los ciudadanos, no puede gozar de los mismos reconocimientos y protecciones legales que sus pares heterosexuales y no pueden gozar de las mismas oportunidades económicas y laborales. Ello tiene por efecto problemas y trastornos psicológicos, violencia física y menos oportunidades de desarrollo profesional e ingresos económicos.

Como demostramos también, la escuela es un foco de producción y reproducción de la homofobia presente en la sociedad. Tal situación debe ser atacada y cambiada por intervención del Estado. Actualmente, los niños LGB sufren de maltratos por vía del acoso homofóbico. Además, atienden a una escuela que está diseñada únicamente para representar personas heterosexuales y que omite la existencia de personas distintas. Los niños tienen peores resultados académicos, afectaciones psicológicas y menores posibilidades de un futuro profesional. Esta situación se trata de un caso de discriminación estructural que justifica la necesidad de que el Estado ejerza acciones positivas y políticas públicas para revertirlo.

Diversos votos de la Corte Suprema, en una reciente sentencia frente a la acción popular contra el enfoque de género incorporado en el Currículo Educativo, han establecido en relación a la discriminación contra la mujer que "el Currículo Nacional de Educación Básica CNEB, aprobado por la Resolución Ministerial 281 -2016-MINEDU, contienen una política de Estado que se encuentra en sintonía con los principios constitucionales de dignidad, igualdad y no discriminación, desarrollados anteriormente, pues el enfoque de igualdad de género tiene como objetivo crear conciencia en los educandos de la importancia de eliminar los prejuicios y estereotipos que sustentan actualmente las desigualdades entre hombres y mujeres" (Corte Suprema, 2019, Voto del Magistrado Bustamante Zegarra, Vigésimo tercero). Esta misma lógica debe aplicarse a los niños LGB.

Segundo, una escuela en la que no se protege a los niños de orientación sexual 
Educación LGB+. El derecho fundamental a educación básica contra la discriminación por orientación sexual

LGB+ Education. The fundamental right to a basic education against discrimination based on sexual orientation

no-normativa es una escuela en que existe discriminación indirecta. Para ello, podemos plantear el cumplimiento de las condiciones del test: a) un parámetro de comparación grupal, b) un trato igualitario y c) una particular desventaja; todo ello sin justificación objetiva y razonable bajo un criterio de proporcionalidad.

a) El parámetro de comparación de los niños LGB son los niños heterosexuales. De cara a la escuela, ambos grupos se componen de pupilos que requieren ser educados para su desarrollo en adultos autónomos en un marco de respeto a sus derechos fundamentales. Ambas son situaciones análogas de cara a la finalidad de la medida bajo análisis (Tribunal Constitucional del Perú, 26 de marzo de 2003, párr. 3.2; Tribunal Europeo de Derechos Humanos, 31 de marzo de 2009, párr. 27).

b) Actualmente, la educación se ofrece a todos los niños por igual, sin hacer distinción a los niños LGB de los niños heterosexuales. No cabe duda de que se trata de una medida administrativa neutra o igualitaria que trata a ambos grupos de niños por igual.

c) La educación actual afecta de forma particular a los niños LGB. El Tribunal Constitucional no ha requerido la demostración de estadística o data dura que compare las situaciones de ambos grupos, sino que se debe constatar in abstracto el riesgo del impacto negativo en el grupo afectado (Fredman, 2011, pág. 186-188; Tribunal Constitucional del Perú, 6 de noviembre de 2008, párr. 54.). Este criterio se justifica en la facilidad probatoria para las víctimas y la ausencia de data en el Perú. Sin perjuicio de ello, en el caso de la discriminación por orientación sexual en la escuela, el impacto negativo del grupo afectado frente al parámetro de comparación se encuentra científicamente documentado. El sistema escolar actual causa una particular desventaja contra los niños LGB por dos motivos.

Primero, los niños de una escuela que no sea inclusiva reciben educación de peor calidad. No adquieren contenidos relevantes para el desarrollo de su propia identidad, en tanto que la información sobre la sexualidad, familia y derechos de los heterosexuales se refiere únicamente a personas heterosexuales, fallando en atender las necesidades de información de los niños no-heterosexuales. En ese aspecto, los estudios de Kosciw (2016, pág. 65; 2014, pág. 66-71) revelan el impacto de la presencia o ausencia de un currículo inclusivo en la escuela: El $40.4 \%$ de los estudiantes educados con un currículo inclusivo se sintieron inseguros debido a su orientación sexual, comparado con el $62.6 \%$ en otras escuelas. Hubo menos abstencionismo. En las escuelas con un currículo inclusivo hubo $18.6 \%$ de abstención por sentirse inseguro o incómodo, frente al $35.6 \%$ en otras escuelas. Los alumnos LGB, además, tuvieron mejores logros académicos en las escuelas con un currículo inclusivo. Asimismo, un mayor porcentaje manifestó la intención de continuar sus estudios luego de terminar la escuela.

Segundo, según hemos demostrado supra, una educación que no atiende las diferencias de identidad sexual se convierte en un factor del acoso escolar homofóbico y los daños físicos y psicológicos de los niños no-heterosexuales.

d) Finalmente, no existe justificación para permitir dicha diferenciación.

En ese sentido, queda demostrado que la educación actual, que no afronta debidamente la existencia ni los problemas particulares que afrontan los niños LGB, los discrimina. En base a ello, del derecho a la igualdad podemos derivar un derecho fundamental a la educación contra la discriminación por orientación sexual.

\subsection{Derecho a la educación}

La Constitución peruana, entre el artículo 13 al 19, regula expresamente el derecho de la educación en diversas disposiciones referidas a distintos aspectos y etapas del proceso educativo.

Ahora bien, no existe texto en la Constitución que defina qué es la educación ${ }^{(3)}$. Desde el punto de vista de la teoría

(3) La Ley General de Educación, Ley 28044, establece una definición más amplia en la medida que agrega como fines específicos a la protección de la familia y la comunidad latinoamericana:

"Artículo 2.- Concepto de la educación. La educación es un proceso de aprendizaje y enseñanza que se desarrolla a lo largo de toda la vida y que contribuye a la formación integral de las personas, al pleno desarrollo de sus potencialidades, a la creación de cultura, y al desarrollo de la familia y de la comunidad nacional, latinoamericana y mundial. Se desarrolla en instituciones educativas y en diferentes ámbitos de la sociedad."

Luego, en su artículo 9 recoge los fines de la educación más cercanos a la definición desde el principio de igual dignidad de las personas:

"Artículo 9.- Fines de la educación peruana. Son fines de la educación peruana: 
educacional, es posible definir la educación como "una acción organizada hacia unos fines en la que se ejerce una influencia intencional sobre los humanos que pretende ayudarles a realizar unas metas individuales y sociales" (Colom Cañellas, 1997, pág. 21-25).

A nivel internacional no se ha definido en tratados qué se debe entender por educación. Sin embargo, la UNESCO ha definido el término de forma amplia como "el proceso global de la sociedad, a través de los cuales [sic] las personas y los grupos sociales aprenden a desarrollar conscientemente en el interior de la comunidad nacional e internacional y en beneficio de ellas, la totalidad de sus capacidades, actitudes, aptitudes y conocimientos" (UNESCO, 1974; Beiter, 2006, pág. 18). El Tribunal Europeo de Derechos Humanos ha señalado que la educación bajo el Derecho europeo de Derechos Humanos comprende "the whole process whereby, in any society, adults endeavour to transmit their beliefs, culture and other values to the young"(4) (Tribunal Europeo de los Derechos Humanos, 25 de febrero de 1982).

En esa línea, el Tribunal Constitucional ha definido a la educación desde la Constitución como un derecho. Esto es, "la facultad de adquirir, recibir o transmitir información, conocimientos y valores a efectos de guiar u orientar el desarrollo integral de la persona, así como habilitarlas para sus acciones y relaciones existenciales, vinculada directamente al desarrollo económico, social y cultural del país" (Tribunal Constitucional del Perú, 16 de abril de 2014, párr. 50).

A efectos de delinear el concepto de educación, resulta necesario atender a su fundamento en los principios de justicia. El Tribunal Constitucional ha señalado que "de conformidad con los artículos 13 y 14, los fines constitucionales del proceso educativo son: a) promover el desarrollo integral de la persona, b) promover la preparación de la persona para la vida y el trabajo, y c) el desarrollo de la acción solidaria." (Tribunal Constitucional del Perú, 17 de octubre de 2007, párr. 13) Estos tres fines, en realidad son formulaciones del principio de igual libertad que justifica o fundamenta el derecho a la educación.

Como señalamos, la ruleta de la vida otorga beneficios y perjuicios a las personas sin ninguna justificación de carácter moral. Es un principio de justicia entonces paliar los efectos de dichos hechos fortuitos para que las personas puedan efectivamente ser responsables por su propia vida y permitir así el igual respeto a la dignidad de todos. Precisamente los derechos sociales buscan eliminar aquellas condiciones que son barreras fortuitas a la libertad de las personas. Sobre este punto el Tribunal señala lo siguiente:

"La educación pública, específicamente, es un inmejorable instrumento para la Justicia Social, concretando el principio de Igualdad de Oportunidades. Corresponde al Estado privilegiar sus recursos para brindar a los hijos de los niveles menos favorecidos en la sociedad educación de calidad, permitiéndoles la posibilidad de labrarse un futuro distinto al de sus padres, la consolidación de sus proyectos de vida en un contexto de creatividad, competencia y responsabilidad social" (Tribunal Constitucional del Perú, 16 de abril de 2014, párr. 51).

Se trata de la búsqueda de la igualdad de oportunidades. Entre otras disposiciones relacionadas con este punto, el Pacto Internacional de Derechos Económicos Sociales y Culturales señala que "la enseñanza superior debe hacerse igualmente accesible a todos, sobre la base de la capacidad de cada uno, por cuantos medios sean apropiados, y en particular por la implantación progresiva de la enseñanza gratuita". En ese sentido, en el marco de la UNESCO en abril de 1990 se suscribió la declaración de Educación para Todos en la cual se establecieron como principios que todos los pupilos tienen el derecho de gozar de una educación de calidad, que permita atender sus necesidades sin discriminación. (World Conference on Education for All, 1990).

Para desenvolverse y sostenerse en la esfera política, económica y cultural de las sociedades actuales, las personas requieren adquirir diversos conocimientos básicos desde temprana edad. Como señala la profesora Levinson (1999), "In many cases,

a) Formar personas capaces de lograr su realización ética, intelectual, artística, cultural, afectiva, física, espiritual y religiosa, promoviendo la formación y consolidación de su identidad y autoestima y su integración adecuada y crítica a la sociedad para el ejercicio de su ciudadanía en armonía con su entorno, así como el desarrollo de sus capacidades y habilidades para vincular su vida con el mundo del trabajo y para afrontar los incesantes cambios en la sociedad y el conocimiento.

b) Contribuir a formar una sociedad democrática, solidaria, justa, inclusiva, próspera, tolerante y forjadora de una cultura de paz que afirme la identidad nacional sustentada en la diversidad cultural, étnica y lingüística, supere la pobreza e impulse el desarrollo sostenible del país y fomente la integración latinoamericana teniendo en cuenta los retos de un mundo globalizado".

(4) Traducción libre: "todo el proceso por el que, en cualquier sociedad, los adultos se dedican a transmitir sus creencias, cultura y otros valores a los jóvenes" 
Educación LGB+. El derecho fundamental a educación básica contra la discriminación por orientación sexual

LGB+ Education. The fundamental right to a basic education against discrimination based on sexual orientation

having a particular job or career will constitute an intrinsic realization of part of their conception of the good; for many others, having a job will be an extrinsically necessary means of earning the resources required for realizing their chosen way of life"(5) (pág. 137). Es decir, desde el punto de vista moral, un requisito indispensable para la autonomía es que la persona tenga la capacidad de sobrevivir por sí misma y, para ello, es fundamental la preparación en aquellas materias que permitan al niño convertirse en un adulto productivo.

El Tribunal señala que "el fin secundario de la formación de la persona para que pueda llevar una vida normal, útil y de sacrificio en la comunidad, fortaleciendo el sentido de libertad, así como el de sus responsabilidades." (Tribunal Constitucional del Perú, 6 de abril de 2014, pág. 50) Esta finalidad se condice con la recogida en el Pacto Internacional de Derechos Económicos, Sociales y Culturales, en cuyo artículo 13 se indica que "la educación debe capacitar a todas las personas para participar efectivamente en una sociedad libre".

Por supuesto, ser adultos autónomos no solo significa contar con conocimientos que permitan incorporarse a la fuerza laboral o generar ingresos económicos. Ser un adulto autónomo, que puede hacerse responsable de su propia vida involucra estar en la capacidad de examinar los valores a los cuales decidir adherirse para llevar una vida buena (Levinson, 1999, pág. 22-35). Para desarrollarse como personas autónomas y agentes en las sociedades plurales contemporáneas, los niños deben formarse y adquirir conocimientos para que puedan comprender y reexaminar sus propios valores. Únicamente así, las personas se encuentran en la posibilidad real de llevar efectivamente las riendas de su propia vida.

En esa línea, el Tribunal define al "fin primario de la educación corno la conquista de la libertad interior" (Tribunal Constitucional del Perú, 16 de abril de 2014, párr. 50). Este fin ha sido reconocido por el Pacto Internacional de Derechos Económicos, Sociales y Culturales. El artículo 13 señala que "la educación debe orientarse hacia el pleno desarrollo de la personalidad humana y del sentido de su dignidad".

Esto, por supuesto, no puede significar que los pupilos se conviertan en tabulas rasas y que dejen de lado los valores provenientes del hogar y de su comunidad. En una sociedad plural y libre, se deben respetar las valoraciones particulares de todas las personas, en tanto estas a su vez se enmarquen en principios de tolerancia y razonabilidad con los valores y los derechos de los demás. Lo que la educación debe permitir es que dicha valoración sea efectivamente libre y no producto de un adoctrinamiento servil (Callan, 1997, pág. 152).
Un Estado liberal y plural, asimismo, requiere que sus ciudadanos respeten el marco de tolerancia de la pluralidad de valoraciones de formas de llevar una vida buena. Para ello, resulta necesario que en las escuelas exista educación cívica y en derechos humanos. Las personas no pueden valorar lo que no conocen. La educación, en ese sentido, juega un rol muy importante para transmitir este tipo de conocimiento desde temprana edad y lograr la adhesión racional de los adultos al cumplimiento de la Constitución y los principios base de una sociedad plural (Gutmann, 1987, pág. 59-67).

Como señala el Tribunal Constitucional, "el ideal de la educación correspondiente a una sociedad democrática y regida bajo parámetros constitucionales debe reforzar lazos de empatía y la noción de igualdad, fomentándose con ello la solidaridad" (Tribunal Constitucional del Perú, 17 de octubre de 2007, párr. 10). Una persona educada estará en mejor capacidad de comprender racionalmente la necesidad de vivir en una sociedad libre y justa, lo cual conllevará al respeto de los derechos humanos del resto. La formación ética y en derechos humanos tiene este fin.

Las violaciones de derechos humanos durante el conflicto armado interno en el Perú tuvieron impacto en las disposiciones pertinentes del artículo 14. Sobre el particular la constituyente Helfer Palacios señaló lo siguiente: "Hoy día desgraciadamente tengo que decirlo hemos tenido una de las experiencias más terribles de nuestra vida: hemos visto cómo se excavaba una fosa y se encontraban restos. Es necesario que, en todas las instituciones, tanto civiles como militares, se dé esta educación cívica, ética y de derechos humanos" (Congreso Constituyente Democrático, 1993, pág. 524).

En esa línea, el Pacto Internacional de Derechos Económicos, Sociales y Culturales establece que la educación "debe fortalecer el respeto por los derechos humanos y las libertades fundamentales" y que "la educación debe capacitar a todas las personas para

(5) Traducción libre: En muchos casos, tener un trabajo o carrera constituirá una intrínseca realización de parte de su concepción de lo bueno, para muchos otros, tener un trabajo extrínsecamente significará los medios necesarios para ganar los recursos necesarios para realizar su forma de vida elegida. 
participar efectivamente en una sociedad libre, favorecer la comprensión, la tolerancia y la amistad entre todas las naciones y entre todos los grupos raciales, étnicos o religiosos".

Para adecuarse a dicha justificación, la prestación de la educación por el Estado no puede ejecutarse de cualquier forma, sino que debe cumplir con ciertos estándares. Los estándares de la educación bajo el Derecho Internacional fueron formulados por Katarina Tomasevski, quien fue Relatora Especial de las Naciones Unidas para el Derecho a la Educación y ha sido adoptada como la interpretación del contenido del derecho a la educación por parte del Comité de Derechos Económicos, Sociales y Culturales de las Naciones Unidas (Beiter, 2006, pág. 476; Comité de Derechos Económicos, Sociales y Culturales, 1999). Los estándares son cuatro: disponibilidad, accesibilidad, aceptabilidad y adaptabilidad (Meix Cereceda, 2014, pág. 47; Beiter, 2006, pág. 476).

a) El principio de disponibilidad exige que el Estado asegure la existencia de instituciones y programas educativos suficientes para atender las necesidades de la población. En el Pacto de Derechos Económicos, Sociales y Culturales existen diversas obligaciones de los Estados agrupados en este principio: deben existir escuelas, debe garantizarse el derecho de establecer y dirigir escuelas privadas, deben existir profesores disponibles y calificados, los profesores deben tener derechos laborales y sindicales, y se debe asegurar la libertad académica e institucional (Beiter, 2006, pág. 477). Asimismo, el Comité de las Naciones Unidas ha interpretado que, dependiendo de los recursos del país, "las instituciones y los programas probablemente necesiten edificios u otra protección contra los elementos, instalaciones sanitarias para ambos sexos, agua potable, docentes calificados con salarios competitivos, materiales de enseñanza, etc.; algunos necesitarán además bibliotecas, servicios de informática, tecnología de la información, etc." (Comité de Derechos Sociales Económicos y Culturales, 1999, pág. 3-4).

b) El principio de accesibilidad exige que dichas instituciones y programas educativos estén al alcance de sus destinatarios. Esto requiere la prohibición de discriminación en el acceso, la accesibilidad física (e.g. es una problemática en las zonas rurales nacionales en que los niños tienen que recorrer largas distancias para llegar a sus escuelas) y la accesibilidad económica, vinculada con la gratuidad (Beiter, 2006, pág. 477; Meix Cereceda, 2014, pág. 41-42; Comité de Derechos Económicos Sociales y Culturales, 1999).

c) El principio de aceptabilidad exige que el currículo educativo, i.e. la definición de qué se enseña y cómo se enseña, sean de la mejor calidad, adecuados y pertinentes culturalmente para lograr los fines que justifican la provisión de la educación (Beiter, 2006, pág. 477; Meix Cereceda, 2014, pág. 41-42; Comité de Derechos
Económicos Sociales y Culturales, 1999). En el Pacto de Derechos Económicos, Sociales y Culturales se establece que se deben asegurar estándares de calidad, seguridad y salud; los padres deben poder guiar la educación moral y religiosa de sus hijos conforme a sus convicciones; la instrucción en la lengua materna; el respeto de los derechos humanos en los métodos, contenido y textos de instrucción, así como de los maestros y la aplicación de la disciplina (Beiter, 2006, pág. 477).

d) El principio de adaptabilidad exige que el currículo esté diseñado para atender las necesidades particulares de sus receptores. Esto significa que el currículo específico debe construirse de forma que entienda las características de los niños a quiénes se dirige y se engarce en su propio mundo de vida para lograr un mejor aprendizaje (Meix Cereceda, 2014, pág. 41-42; Cotino, 2012, pág. 898). Este principio reconoce la cultura y la identidad como parte del respeto que se debe a la igual dignidad de todas las personas. Por ejemplo, los programas educativos y la infraestructura deben adecuarse a las necesidades de los niños discapacitados. Los horarios y los programas deben adaptarse a los niños que deben trabajar para sobrevivir (Beiter, 2006, pág. 509-510).

El contenido del derecho a la educación expuesto justifica la existencia de un derecho a una educación que erradique la discriminación por orientación sexual. Primero, ello es necesario para que los niños puedan desarrollarse en adultos que se hacen responsables de su propia vida. Segundo, ello es mandatorio en base a la obligación de brindar formación ética y en derechos humanos. La educación inclusiva enseña a los niños a respetar a todos por su igual valor y dignidad humana, sin discriminación por orientación sexual. Tercero, ello es requerido, además, por el principio de aceptabilidad. Cuarto, ello es requerido por el principio de adaptabilidad de la educación.

a) Primero, la educación LGB+ es fundamental para el desarrollo de los niños LGB en adultos autónomos que 
Educación LGB+. El derecho fundamental a educación básica contra la discriminación por orientación sexual

LGB+ Education. The fundamental right to a basic education against discrimination based on sexual orientation

puedan hacerse responsables de sus propias vidas (Palmer, 2017, pág. 67; Biegel y Kuehl, 2010, pág. 55; Poteat, 2017, pág. 23). Los estudios actuales demuestran que en las escuelas en que se incorporó un currículo escolar inclusivo, las percepciones positivas de las personas LGBT mejoraron. Los niños LGBT aprendieron a reconocerse como miembros valiosos de la escuela y la sociedad. Al respecto, Kosciw (2016) señala que "incluir temática LGBT en el currículo en una manera positiva puede hacer que los alumnos LGBT se sientan miembros más valiosos de la comunidad escolar y puede también promover más sentimientos positivos sobre la problemática y las personas LGBT entre los pares, resultando así en un ambiente escolar más positivo" (pág. 66-71). Como señala el profesor Palmer (2017): "Un currículo inclusivo valida la existencia de una población usualmente invisible, reforzando así el valor de los individuos LGBT en sí mismos y enviando un poderoso mensaje a los estudiantes LGBT sobre su valía" (pág. 67). En esa línea, el profesor McGarry (2013) destaca el papel del currículo educativo como espejo para los alumnos, mediante el cual los niños LGB pueden identificarse y validar su propia identidad. Se ha demostrado, asimismo, que el currículo inclusivo permite que los niños se involucren en la escuela, reduciendo el abstencionismo escolar (Kosciw, 2016, pág. 66-71).

Por el contrario, la escuela que ignora la existencia de los niños LGB reproduce el mensaje de que las sexualidades no-normativas son negativas y anormales. Las personas que no se ajustan a las reglas sociales son excluidas y forzadas a un plano marginal, de rechazo y violencia. Precisamente los niños con orientación sexual disidente crecerán para sufrir dichos problemas psicológicos en su vida adulta, truncamientos a su proyecto de vida y menores perspectivas económicas que sus pares heterosexuales. Al respecto, el profesor Palmer (2017) es muy claro al señalar que "schools produce and reproduce heterosexuality as the only "normal" and viable option (Kejily, 2002) while simultaneously reinforcing rigid gender norms that marginalize those who do not conform to the strict binary system of gender (Connel, 1996)" (pág. 59).

El Comité de Naciones Unidas para los Derechos del Niño (2013) ha señalado además que la educación sexual es fundamental para proteger el derecho a la salud de los niños:

\footnotetext{
“22. Los adolescentes tienen el derecho de acceder a información adecuada esencial para su salud y desarrollo y para que puedan participar significativamente en la sociedad. Es la obligación de los Estados parte el asegurar que todas las niñas y niños adolescentes, tanto dentro como fuera de la escuela, sean suministrados con, y no se les deniegue, información precisa y apropiada sobre cómo proteger su salud y desarrollo y sobre cómo practicar comportamientos saludables. Ello debe contener información sobre el uso
}

y abuso de, tabaco, alcohol y otras sustancias; conductas sociales y sexuales seguras y respetuosas, dieta y actividad física".

Una educación que pretenda el desarrollo de los niños no-heterosexuales en adultos autónomos debe entonces brindar contenido adecuado a la sexualidad de todos los pupilos. Estos deben estar en la posibilidad de comprender que la sexualidad es diversa, que la heterosexualidad no es la única variable humana, sino que los seres humanos pueden ser homosexuales, bisexuales, pansexuales o parte de alguna variable del espectro. Los niños no-heterosexuales deben conocer las particularidades de su propia sexualidad, de forma adecuada a su edad, deben comprender los riesgos y las medidas de protección para el ejercicio pleno de su sexualidad de forma segura y responsable (Formby, 2016).

Esto, por supuesto, no significa una educación sexual basada en la prevención de riesgos. Lo que plantea la educación sexual holística, por el contrario, sigue el lema "Long live love." El enfoque debe ser la consideración de la sexualidad como una fuente de felicidad. El objetivo es "developing and strengthening the ability of learners to make conscious, satisfactory, healthy and respectful choices regarding relationships and sexuality." (Ketting et al, 2015; Frans, 2016).

b) La escuela LGB+ es necesaria para brindar efectivamente una educación cívica y en derechos humanos. De acuerdo al Tribunal Constitucional, "el ideal de la educación correspondiente a una sociedad democrática y regida bajo parámetros constitucionales debe reforzar lazos de empatía y la noción de igualdad, fomentándose con ello la solidaridad." (Tribunal Constitucional del Perú, 17 de octubre de 2007, pág. 10) Una persona educada estará en mejor capacidad de comprender racionalmente la necesidad de vivir en una sociedad libre y justa, lo cual conllevará al respeto de los derechos humanos del resto. La formación ética y en derechos humanos tiene este fin.

En esa línea, el Pacto Internacional de Derechos Económicos, Sociales y Culturales establece que la educación "debe fortalecer el respeto por los 
derechos humanos y las libertades fundamentales" y que "la educación debe capacitar a todas las personas para participar efectivamente en una sociedad libre, favorecer la comprensión, la tolerancia y la amistad entre todas las naciones y entre todos los grupos raciales, étnicos o religiosos".

La Corte Interamericana de Derechos Humanos ha señalado expresamente en su Opinión Consultiva No. 37 que "es obligación de los Estados erradicarlas [la cultura, religión y tradición que perpetúan el estigma contra personas LGBTI] cultivando un sentido de empatía por la orientación sexual y la identidad de género como parte inherente de toda persona lo cual "invita a reevaluar el contenido educativo y los libros de texto, así como a elaborar herramientas y metodologías pedagógicas, para promover una mentalidad abierta y el respeto de la diversidad biológica de los seres humanos" (Corte Interamericana de Derechos Humanos, 2018, pág. 40).

En el mismo sentido, el Magistrado Wong Abad de la Corte Suprema peruana destacó que "solo la educación en los valores constitucionales puede librarnos de considerar que los demás deben constreñirse a nuestras particulares creencias o valores y que, por consiguiente, quien se aparta de ellos debe ser castigado o repudiado de alguna forma" (Corte Suprema 2019: Voto del Magistrado Wong Abad, Décimo Quinto). Asimismo, en el caso de las personas LGBTI, señaló que:

"El asunto, por tanto, más allá de las categorías que puedan formularse y de las discusiones conceptuales que aquellas pudieran suscitar se reduce a términos muy sencillos: si comprobamos en nuestra sociedad la existencia de personas heterosexuales, homosexuales, transgénero o intersexuales es nuestra obligación, por mandato, humano, convencional y constitucional, brindarles el mismo respeto y consideración que a cualquier otro ser humano. Por consiguiente, el Currículo Nacional de la Educación Básica tampoco puede ser acusado de inconstitucional por inculcar en nuestros estudiantes el respeto por las diferentes formas de expresión de la sexualidad. Más aún, la incorporación en el indicado currículo del denominado Enfoque de Género no hace más que responder a la obligación del Estado de promover una cultura de tolerancia en el marco de lo ordenado por la Convención Americana" (Corte Suprema 2019, Voto del Magistrado Wong Abad, Vigésimo Octavo).

No cabe duda, entonces, de que las escuelas deben buscar exponer a los niños al máximo respeto de los derechos humanos para permitir un convencimiento racional como adultos autónomos. En ese sentido, la erradicación de la discriminación contra las personas LGB requiere la implementación de un currículo inclusivo. Los niños no pueden formarse en ciudadanos tolerantes y razonables que conviven pacíficamente en un Estado plural, si no están expuestos a diferentes formas de vida, como la vida de las personas LGB+. Por tanto, para que la educación pueda lograr formar a los niños en derechos humanos es necesario la educación en contra de la discriminación por orientación sexual.

c) Tercero, el principio de aceptabilidad exige que la escuela sea de la mejor calidad para lograr los fines que justifican la provisión de la educación (Meix Cereceda, 2014, pág. 41-42). En tal sentido, una escuela que omita contenido relativo a la diversidad de orientación sexual falla en lograr la calidad necesaria para el desarrollo de los niños no-heterosexuales. No logra prepararlos para su vida de adultos ni logra brindar herramientas para reconocer su propia valía como seres humanos cuya sexualidad es igual de valiosa que la de todos.

d) El principio de adaptabilidad exige que la escuela esté diseñada para adaptarse a las necesidades particulares de sus receptores. Es parte del contenido entretejido con el principio de igualdad. Esto significa que el currículo específico debe construirse de forma que entienda las características de los niños a quiénes se dirige y se engarce en su propio mundo de vida para lograr un mejor aprendizaje (Meix Cereceda, 2014, pág. 41-42; Cotino, 2012, pág. 898). Este principio reconoce la cultura y la identidad, incluyendo la orientación sexual, como parte del respeto que se debe a la igual dignidad de todas las personas.

De acuerdo a lo señalado, es claro que la educación debe ser inclusiva para los niños LGB y debe protegerlos de la discriminación. Esta es el único entendimiento compatible con los principios de la educación y con su justificación desde los principios de justicia que lo sustentan.

\subsection{Implementación}

Ahora bien, ¿cómo se traduce en la realidad un derecho a que la educación se encargue de erradicar la discriminación por orientación sexual?

Existen diversas estrategias que atacan los respectivos factores que contribuyen a la prevalencia de la discriminación en la escuela. Curiosamente, antes que por parte 
Educación LGB+. El derecho fundamental a educación básica contra la discriminación por orientación sexual

LGB+ Education. The fundamental right to a basic education against discrimination based on sexual orientation

del Estado, las iniciativas en Estados Unidos para combatir la discriminación en la escuela se dieron inicialmente por parte de los propios alumnos. Lo que sigue es una estrategia estatal coordinada para reformar el currículo educativo, capacitar a los maestros y estructurar una política de protección a los niños LGB.

La primera y actualmente una de las principales estrategias para la erradicación de la discriminación en la escuela han sido las Gay-Straight Alliances o GSA, por sus siglas. Las GSA se tratan de clubs o grupos de niños homosexuales, bisexuales, transgénero y heterosexuales que desarrollan diversas actividades extracurriculares para promover la tolerancia en la escuela y en la comunidad, o que simplemente pasan el tiempo en un espacio seguro (Sadowski, 2016, pág. 8-9). La primera GSA documentada empezó en Concord, Massachusetts, en 1989 y actualmente existen más de 3000 en Estados Unidos. El 22\% de niños en Estados Unidos reportó en 2007 contar con una GSA en su escuela (Meyer, 2010, pág. 76).

Diversos estudios han demostrado que la presencia de una GSA en la escuela contribuye a la mejora en el clima escolar, en la percepción de seguridad de los niños de orientación sexual disidente, así como en la salud mental y el desempeño académico (Sadowski, 2016, pág. 8-9; Meyer, 2010, pág. 76). Los niños LGB que participaron en estos grupos crecieron para ser adultos con menos problemas psicológicos que sus pares LGB. El estudio del Dr. Palmer resume los principales hallazgos a la fecha: menos comentarios anti-LGB de sus compañeros, menores niveles de victimización dentro de la escuela, se sienten más seguros en la escuela, faltan menos a clase, se sienten más conectados con la comunidad escolar, se sienten más aceptados por sus pares y se sienten más cómodos hablando de temas LGB con sus profesores. Al dejar la escuela, los adultos jóvenes que tuvieron acceso a una GSA reportan menos depresión, mayor autoestima y mayor continuidad en la educación (Palmer, 2017, pág. 62-63).

Por otro lado, por parte del Estado, cabe en primer lugar implementar el currículo inclusivo. Este es un currículo que incorpora contenido y temática relativa a la orientación sexual y la identidad de género, que ayuda a los alumnos a comprender que la sexualidad es diversa y ello es normal (Mayo, 2013, pág. 161; Flinders y Thornton, 2004, pág. 307). El programa de Educación para todos de la UNESCO, enfocado en lograr la erradicación de la discriminación de la escuela, destaca la necesidad de que el respeto y la no-discriminación sean materias transversales integradas a todas las demás materias básicas. Al respecto, señala lo siguiente:

"La experiencia ha mostrado que el currículo exitoso en enseñar respeto y luchar contra todo tipo de discriminación es aquel que está integrado en cada aspecto del currículo existente. Existen dos razones para ello. Primero, no es práctico para los educadores de los últimos años de la escuela primaria y de la secundaria pensar en enseñar respeto y lucha contra la discriminación como entidades separadas. En dichos niveles, en particular, el proceso educativo se enfoca en cuerpos eclécticos de conocimiento y habilidades y la especialización es casi imposible para los maestros. Segundo, hacer la lucha contra la discriminación y enseñar respeto como partes integrales del currículo existente envía el mensaje de que dicha problemática es esencial. Al enseñar estos conceptos como materias separadas, los pupilos pueden pensar que los problemas de injusticia, tolerancia, empoderamiento y pensamiento crítico no son tan importantes como aprender las materias básicas" (UNESCO, 2014, pág. 37).

La profesora Meyer presenta una propuesta para integrar temas sobre sexualidad y género transversalmente en el currículo, acorde con el paradigma de educación multicultural y con la guía de la UNESCO de Educación para todos (2010, pág. 6-76).

a) Roles de género: Los niños usualmente aprenden desde el preescolar y los primeros años de la educación primaria a clasificar roles de género. Por ejemplo, desde niños se solicita a los niños que identifiquen actividades, juegos o intereses que corresponden a las niñas y actividades, juegos o intereses que corresponden a los niños. La profesora Meyer sugiere que "in order to help students feel valued and included in all of their gender diversity, elementary school teachers can incorporate lessons and activities that celebrate this diversity and challenge narrow gender stereotypes".

b) Paternidad y familia: Igualmente, los niños reciben únicamente imágenes de familias tradicionales, pese a que muchos niños viven con padres o madres homosexuales, padres solteros o familias distintas. La profesora Meyer sugiere, con el objeto de combatir la homofobia desde la escuela, la necesidad de incluir modelos de familias de padres homosexuales, por ejemplo, desde la literatura infantil, considerando que en la actualidad existen una serie de libros que ofrecen perspectivas de niños viviendo en familias diversas. 
c) Literatura: Particularmente para la educación secundaria, la profesora Meyer sugiere dos vías para incorporar contenido sobre diversidad sexual y género en la clase de literatura. La primera y más obvia es mediante la lectura de textos, novelas, poemas o cuentos que incluyan representaciones de diferencias en orientación sexual, sexo o identidad de género. La segunda vía es mediante la lectura queer de textos tradicionales. Por ejemplo, la profesora Meyer sugiere la posibilidad de encontrar extractos que reflejan situaciones homoeróticas en Romeo y Julieta, así como situaciones que reflejen la heteronormatividad de la época. Al respecto, la autora señala "this exposure may also open students' own creative lenses up and allow them to write about their own experiences in relationships or gendered identities in new ways".

d) Historia y ciencias sociales: La profesora Meyer destaca cómo muchos eventos históricos tuvieron de protagonistas a personas LGB y sin embargo usualmente son excluidos del currículo. Por ejemplo, las víctimas gays y lesbianas del holocausto nazi, o el movimiento por los derechos LGB que surgió a partir de los años 1980. En el caso peruano, por ejemplo, pocas veces se habla de las víctimas LGB del terrorismo de Sendero Luminoso y el MRTA. Tales episodios pueden ser incluidos en las clases de Historia para dar visibilidad a la problemática de la diversidad sexual.

e) Ciencias Naturales: Desde las Ciencias Naturales es posible que los niños y adolescentes aprendan sobre los recientes descubrimientos científicos sobre la diversidad sexual, su origen y los factores que la determinan. Igualmente es posible aprender sobre los límites de las ciencias duras para comprender dichos temas. La profesora Meyer también sugiere una revisión de información anticuada y condicionada por las normas de género, por ejemplo, el discurso que se sigue transmitiendo sobre el género de las hormonas. Muchos textos siguen refiriéndose a la testosterona como la hormona masculina y al estrógeno como la hormona femenina, cuando desde 1930 se conoce que ambas están presentes en todas las personas.

f) Matemáticas: En este caso, la profesora Meyer sugiere la inclusión de situaciones y actores homosexuales en la formulación de problemas matemáticos o estadísticas relacionadas con situaciones de personas homosexuales. Ello con el objetivo de generar visibilidad y normalizar la homosexualidad.

g) Educación sexual: Diversos autores han destacado como es usual que la única mención a la homosexualidad en la escuela sea en la clase sobre el SIDA y el VIH en educación sexual. Esto contribuye a la estigmatización de las minorías sexuales. Por el contrario, una educación sexual integral debe incluir contenido relativo a la diversidad sexual, a los estereotipos sobre sexualidades normales y desviadas, así como contenido que atienda los requerimientos específicos de salud y bienestar sexual para personas homosexuales.

Los estudios actuales demuestran que en las escuelas en que se incorporó un currículo escolar inclusivo, el clima escolar es sustancialmente mejor y el acoso escolar es menor frente a escuelas que no incorporaron un currículo inclusivo. Al respecto, el profesor Kosciw (2016) señala que "including LGBrelated issues in the curriculum in a positive manner may make LGB students feel like more valued members of the school community, and it may also promote more positive feelings about LGB issues and persons among their peers, thereby resulting in a more positive school climate" (pág. 65).

En el Perú, el Currículo Nacional de la Educación Básica 2016 por primera vez tiene como uno de los objetivos de aprendizaje de los niños la comprensión y valoración de la propia identidad sexual; así como el rechazo a toda forma de discriminación por orientación sexual. Esto representa un avance importante en el reconocimiento de la diversidad sexual y la erradicación de la discriminación.

Sin embargo, el currículo actual no representa aún un punto de Ilegada. El tratamiento de la temática sobre orientación sexual es aún escueto y acotado a un solo programa curricular y para los últimos años de educación secundaria. Si se compara el Currículo Nacional de la Educación Básica con, por ejemplo, la propuesta de la profesora Meyer, que es acorde a las investigaciones de la educación multicultural y a la propuesta de la UNESCO sobre Educación para todos, se encuentra que aún existe la posibilidad de incorporar contenidos relativos a la diversidad sexual en diversas áreas curriculares.

a) Primero, es posible extender el tratamiento de la diversidad sexual a todas las etapas de la educación. En lugar de restringir el tratamiento de la identidad sexual y el rechazo a la discriminación sexual a los últimos años de secundaria, es posible aprender sobre la diversidad sexual y la diversidad de familias y parejas desde los primeros años de la educación inicial. La profesora Meyer sugiere la introducción 
Educación LGB+. El derecho fundamental a educación básica contra la discriminación por orientación sexual

LGB+ Education. The fundamental right to a basic education against discrimination based on sexual orientation

de cuentos e historias con familias diversas y de parejas homosexuales desde las primeras infancias.

b) Segundo, es posible extender el tratamiento de la diversidad sexual a distintas áreas, además de "Desarrollo personal, ciudadanía y cívica". Tal como sugiera la propuesta del currículo inclusivo, es posible incorporar contenidos relativos a la diversidad sexual en el área de matemática, mediante la introducción del análisis de cifras sobre la población LGB. Es posible incorporar contenidos relativos a la diversidad sexual en el área de ciencia y tecnología. Es posible incorporar contenido relativo a la diversidad sexual en el área de comunicación. También en el área de ciencias sociales. Entonces, es posible lograr que la diversidad sexual sea un contenido transversal al programa curricular.

Entonces, es posible señalar que aún existe un largo camino para lograr que el currículo escolar verdaderamente deje de guardar silencio sobre la orientación sexual y permita superar el círculo de reproducción de la discriminación por orientación sexual.

Adicionalmente, es necesario capacitar a los profesores. Un profesor puede hacer la diferencia al actuar en contra del acoso escolar homofóbico, apoyar a los alumnos LGB, incluir contenido LGB en sus clases y promover la creación de espacios seguros como las GSA. La presencia de un adulto que apoye a niños marginalizados por sus pares puede crear una gran diferencia en el bienestar psicológico y en el desempeño académico del niño. Los estudios también son claros en ese respecto, de acuerdo con lo que señala el profesor Palmer (2017):

"Los educadores pueden demostrar apoyo a los jóvenes LGB de diferentes formas, incluyendo la intervención en los insultos anti LGBT, acoso y violencia escolar; así como acciones preventivas o proactivas, como mostrar signos visuales de apoyo a las personas LGBT (e.g. etiquetas de espacios seguros) y participar en educación y promoción en las escuelas respecto a la problemática LGBT. Estas acciones mejoran el ambiente de aprendizaje para jóvenes LGBT, quienes reportan menores niveles de violencia (Murdock \& Boch, 2005), menos abstencionismo (Kosciw et al., 2014; Seelman, Walls, Hazel, \& Wisneski, 2011), y un aumento en los sentimientos de conexión a la escuela (Diaz, Kosciw, \& Greytak, 2010; Murdock \& Bolch, 2005) cuando reciben apoyo de sus educadores y de los estudiantes" (pág. 66).

La Jericho Middle School, en New York, ha desarrollado una política de creación de espacios seguros y capacitación de profesores desde que se encontró en 2003 que la mayor parte del acoso escolar era homofóbico. La profesora Elisa Waters ha conducido un programa de capacitación para profesores en asuntos LGB y ha organizado una serie de conferencias y talleres para generar escuelas inclusivas para alumnos LGB.
En más de 10 años desde que empezó el programa, diversas profesoras han notado la mejora en el clima escolar y en la forma en que los alumnos responden a la temática LGB. En 2013, un alumno de 13 años declaró para el New York Times "I know thousands of things about every single person in this class. We're learning how to make the world a more connected place" (Sadowski, 2016, pág. 39-52).

Finalmente, otro factor importante en la mejora del clima escolar y la erradicación de la discriminación por orientación sexual en la escuela es la existencia de una política escolar específica o que enfrente expresamente el acoso escolar homofóbico. Estas políticas permiten formalizar y establecer procedimientos para que los profesores manejen los casos de acoso escolar y también para que los alumnos reporten dichos casos. Los estudios demuestran que las escuelas en las que existen políticas que enfrentan expresamente la discriminación por orientación sexual, los resultados son mejores que en escuelas con políticas genéricas o sin políticas anti-bullying (Palmer et al., 2017, pág. 66).

Queda claro, entonces, que el Estado, de manos de los propios alumnos y de la sociedad civil, tiene en sus manos cambiar la situación de discriminación que se vive actualmente en las escuelas, a efectos de concretar en la realidad el derecho a que la educación escolar contribuya a la erradicación de la discriminación por orientación sexual.

\section{4. ¿Con mis hijos no te metas?}

En los últimos años se ha venido gestando un movimiento civil/religioso denominado "Con mis hijos no te metas" en reacción a las reformas educativas para la introducción del enfoque de género. Este colectivo se define como "un movimiento ciudadano que nace como reacción a la imposición de la Ideología de Género en nuestros hijos mediante el sector educativo en los diferentes estados

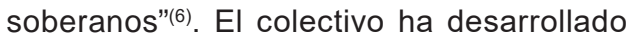

(6) Recuperado el 5 de noviembre de 2019, de https://www.facebook.com/notes/con-mis-hijos-no-te-metas/con-mis-hijos-no-temetas/667269290313659/ 
manifestaciones y acciones judiciales contra las políticas progresistas del Gobierno.

Lo particular de dicho movimiento es que trae a la palestra pública los principales contra argumentos frente a la postura defendida en este trabajo. A continuación, analizamos dicha posición.

\subsection{Ozzymandias, judíos e ideología de género}

En el comic "Watchmen", el genio Ozzymandias se cuestiona cómo unir al mundo en medio de la Guerra Fría de los años 1980 y prevenir así una catástrofe nuclear producto de la guerra entre los Estados Unidos y la Unión Soviética. La respuesta a la que llega es que necesita que el mundo tenga un enemigo común. Para ello crea un monstruo gigante en medio de Manhattan para hacerlo pasar por un alienígena. El plan tiene éxito y la Guerra Fría acaba.

En el mundo real, una estrategia parecida tuvieron los Nazis para unir al pueblo alemán en torno al partido: eliminar al judío. En la década de 1950, el senador estadounidense McCarthy buscó rédito político mediante la alegación de una conspiración comunista en el gobierno. Recientemente Donald Trump ganó las elecciones, entre otras estrategias, gracias a la creación de un enemigo común: el migrante. Como señala Zizek (2012), "Para el fascismo, el 'judío' es el medio de tener en cuenta, de representar su propia imposibilidad: en su presencia real, es únicamente la encarnación de la imposibilidad última del proyecto totalitario (...) La sociedad no está incapacitada para alcanzar su plena identidad a causa de los judíos: lo que se lo impide es su propia naturaleza antagónica, su propio bloqueo inmanente, y 'proyecta' esta negatividad interna en la figura del 'judío'(...) hemos de reconocer en los 'excesos' que se atribuyen a los 'judíos' la verdad sobre nosotros mismos" (pág. 174-175).

No caben dudas entonces, de que la construcción discursiva de un enemigo común permite cohesionar a los colectivos de personas para obtener adhesión política. "La ideología de género" se muestra como una estrategia similar: la construcción discursiva de un enemigo común para cohesionar a un colectivo de personas. Esta estrategia no solo es aprovechada por los líderes del colectivo, sino por varios partidos políticos tradicionales ${ }^{(7)}$.

En este caso el enemigo de la ideología de género es todo planteamiento que defienda derechos de colectivos LGB o preocupaciones por los derechos de las mujeres. Así, bajo la ideología de género se agrupan desde planteamientos liberales, planteamientos críticos, hasta invenciones relativas al nuevo orden mundial y los anunnaki ${ }^{(8)}$.

¿Cómo está construida la ideología de género en este discurso? El colectivo indica que "El postulado principal de esta ideología de género es que nuestra identidad es producto de una construcción social y cultural, aún [sic] lo que se considera como masculino y femenino, rechazando tácitamente la noción de que no existe una verdadera esencia femenina, sino que esto se construye." Vinculado a ello, indica que "ConMisHijosNoTeMetas busca defender la dignidad y respeto de la especie humana, reconociendo nuestro valor absoluto e intrínseco por lo que somos, humanos, y no por cómo algunos pretenden concebir a los humanos". Por otro lado, se indica que "la lucha se expande a una epopeya por el respeto a la libertad humana y la delimitación de los alcances que el estado tiene sobre sus mandantes, los ciudadanos"(9).

Estos extractos reflejan dos ideas principales: (i) la ideología de género es un postulado que plantea que la identidad es cultural, lo cual es falso y malo porque se opone a lo natural, que es lo verdadero y bueno; (ii) el Estado busca imponer esta creencia, lo cual no es legítimo porque atenta contra la libertad. En base a estas dos premisas, se busca evitar los cambios en la política educativa nacional (Márquez y Laje, 2016). Analicémoslas.

El primer postulado es infundado por varias razones. Primero, no todos los defensores de libertades LGB plantean que estas identidades son estrictamente culturales. Como vimos, muchos siguen las aproximaciones esencialistas que plantea el origen biológico y de nacimiento de la homosexualidad.

(7) Recuperado el 5 de noviembre de 2019, de https://www.americatv.com.pe/noticias/actualidad/colectivo-mis-hijos-no-te-metas-realizamarcha-plaza-san-martin-n347128

(8) Recuperado el 5 de noviembre de 2019, de https://www.eluniversal.com.mx/entrada-de-opinion/articulo/jose-crespo/nacion/2016/09/26/ conspiracion-mundial-homosexual https://www.religionenlibertad.com/polemicas/53017/mayor-oreja-ideologia-genero-cimiento-delnuevo.html. https://katecon2006.org/2016/08/10/rockefeller-y-la-ideologia-de-genero/

(9) Recuperado el 5 de noviembre de 2019, de https://www.facebook.com/notes/con-mis-hijos-no-te-metas/con-mis-hijos-no-temetas/667269290313659/ 
Educación LGB+. El derecho fundamental a educación básica contra la discriminación por orientación sexual

LGB+ Education. The fundamental right to a basic education against discrimination based on sexual orientation

Segundo, es innegable que la forma de comportarse, ser y pensar asociados a ser hombre o mujer (i.e. el género) depende de la cultura. Esto además no es contradictorio con el párrafo de arriba. Como señalamos, las ciencias naturales y las ciencias sociales pueden complementarse. Por ejemplo, Jesús tenía el cabello largo, los sacerdotes romanos usan falda y los niños de Sambia en Papúa Nueva Guinea tienen que tomar semen antes de pasar a la pubertad (Herdt, 1981). Todos estos comportamientos no son propios de la masculinidad tradicional occidental, pero sí lo son en determinados tiempos y culturas. Esto es un asunto de identidades y prácticas culturales.

Tercero, es falso que el orden natural sea intrínsecamente bueno. Pues de lo contrario, sería malo que haya medicina porque la muerte por enfermedad es natural y no habría que usar ropa porque la naturaleza nos dio la piel para protegernos del frío.

Lo que importa es que hay personas que se sienten atraídas romántica y sexualmente a personas del mismo sexo. $Y$ esta atracción no genera daños a terceros ni a ellos mismos. Por el contrario, hay muchos terceros que las dañan física y psicológicamente. Y el Estado tiene el deber de proteger su libertad.

El segundo postulado es más interesante porque pone sobre la mesa un clásico caso de colisión de derechos. Veamos.

\section{2. ¿Deben tener los padres plena autonomía para educar a sus hijos?}

Por un lado, no caben dudas de que, como vimos, la imposición del Estado de una política educativa orientada a erradicar la discriminación contra personas LGB+ se encuentra justificada en la necesidad de generar igual libertad para todos los seres humanos. Pero, por otro lado, los padres tienen también un interés en procurarles educación a sus hijos de acuerdo a sus propios valores.

De hecho, el art. 13 de la Constitución señala que "Los padres de familia tienen el deber de educar a sus hijos y el derecho de escoger los centros de educación y de participar en el proceso educativo." El art. 14 señala que "La educación religiosa se imparte con respeto a la libertad de las conciencias." En ese sentido, los artículos 13 y 14 de la Constitución aseguran que los padres puedan tomar decisiones y guiar el proceso educativo de sus hijos. Los padres eligen a qué escuela asisten y participan en el proceso educativo de sus hijos.

Estas disposiciones son coherentes con el Pacto Internacional de Derechos Económicos, Sociales y Culturales, por el cual el Estado debe "respetar la libertad de los padres y, en su caso, de los tutores legales, de escoger para sus hijos o pupilos escuelas distintas de las creadas por las autoridades públicas, siempre que aquéllas satisfagan las normas mínimas que el Estado prescriba o apruebe en materia de enseñanza, y de hacer que sus hijos o pupilos reciban la educación religiosa o moral que esté de acuerdo con sus propias convicciones."

Esto ha llevado a que académicos que postulan las libertades de personas LGB como Alfredo Bullard (2018) coincidan en el punto educativo de "Con mis hijos no te metas":

La decisión de cómo educar a nuestros hijos es de los padres. El Estado la ha expropiado hace décadas arrogándose la facultad de sustituir el criterio del padre por el del burócrata. Si desea que su hija estudie en un colegio del Opus Dei o en uno del Sodalicio, en una escuela marxista o una liberal, o decide, como padre, asumir su educación directamente (homeschooling) en su casa, está en su derecho. Y en consecuencia las escuelas deberían tener el derecho de definir libremente sus contenidos.

Es un derecho de los padres acertar o equivocarse con sus hijos. $Y$ no porque equivocarse sea bueno, sino porque es probable que los burócratas se equivoquen más y peor. Y cuando el burócrata se equivoca, crea monopolios de ideas que el colegio no puede discutir. Nunca he entendido a qué se refieren con "ideología de género", pero sí he sido testigo de ideologías militaristas, religiosas, falsamente moralistas, pro gobierno de turno, socialistas o anti mercado en programas educativos aprobados por el Estado.

Lo que se plantea es que los padres deben tener plena autonomía para ejercer la paternidad sobre sus hijos, lo cual incluye la educación. De ello se derivaría que los padres pueden decidir rechazar completamente la política antidiscriminación del Estado.

Más allá de la falacia de la bola de nieve, de la pendiente inclinada o del hocico de camello(10), esta posición obvia dos puntos importantes: (i) los hijos son también

(10) i.e. atacar un argumento en base a suposiciones de lo que podría ocurrir, como e.g. rechazar el matrimonio gay porque luego significaría legalizar la pedofilia. 
personas con derecho a libertad igualitaria y (ii) las decisiones educativas de una persona impactan en terceros. Así, el interés de los padres colisiona con los derechos de otras personas.

Primero, los niños son personas y por tanto fines en sí mismos (Levinson, 2004, pág. 65-82). Entonces, no pueden ser objetos del derecho de otros. Antes que una libertad de los padres a decidir cómo educarlos, los padres tienen discrecionalidad para ejercer su deber de paternidad o crianza, lo cual permitirá que los niños se transformen en adultos autónomos. Y el ejercicio de esa potestad no puede vulnerar los derechos fundamentales de los niños.

Así como resulta claro que el Estado puede intervenir para evitar que un padre mate a sus hijos, el Estado puede intervenir para proteger a los niños LGB de los daños psicológicos que puedan causar padres homofóbicos (Moschella, 2016, pág. 49-73). De esta manera, una política educativa contra la discriminación es una medida necesaria, mas, quizás, no suficiente, para evitar que padres homofóbicos impongan una escuela homofóbica a sus hijos LGB dañando la integridad psíquica, física y el aprendizaje.

En esa línea, si los padres pudieran impedir que los niños cuenten con conocimientos para estar en capacidad de reexaminar sus valores y hacerse responsables de su propia vida, no se estaría respetando la igual dignidad de los niños como seres humanos. Se estaría subordinando la vida y el futuro de ciertos seres humanos a las decisiones de otros seres humanos (Callan, 1997, pág. 132-162; Moschella, 2016, pág. 119-146). Es por eso que es labor del Estado brindar las herramientas a los hijos para convertirse en adultos autónomos.

Este criterio fue seguido por la sentencia Kjeldsen $v$. Dinamarca. El Tribunal Europeo evaluó si ciertos padres religiosos podían oponerse a la educación sexual ofrecida en las escuelas públicas danesas. Se decidió que primaba el interés público de asegurar que los niños se conviertan en adultos autónomos que puedan guiar las riendas de su vida y que primaba también la necesidad de prevenir embarazos no deseados. El Tribunal señaló que toda instrucción tiene cierto contenido moral; sin embargo, en tanto se mantenga cierto grado de objetividad y apertura a crítica, la educación respetaba el pluralismo valorativo de la democracia. Nada afectaba que los padres puedan guiar en casa la forma de comprender la educación recibida en la escuela por los niños. En ningún caso existía adoctrinamiento a tener relaciones precoces o llevar una vida que para los padres sea inmoral (Tribunal Europeo de los Derechos Humanos, 7 de diciembre de 1976, párr. 54).

Segundo, si el padre homofóbico educa en valores homofóbicos a sus hijos, estos niños se convierten en potenciales agresores de los niños LGB y se reproduce la homofobia en la sociedad que daña las vidas de las personas LGB+. Entonces las decisiones de ese padre homofóbico generan externalidades negativas (Rey, 2018). Ello legitima al Estado a implementar políticas educativas contra la discriminación para evitar esas externalidades.

En ese sentido, falló una decisión de la Corte Suprema de Canadá en la que se consideró ilegal la decisión de un School Board de censurar textos escolares para primer grado de primaria con representaciones de padres homosexuales frente a una objeción de ciertos padres de familia. La Corte interpretó la ley que recogía el principio de secularismo y tolerancia en la educación y determinó que la decisión del School Board atentó contra los derechos de las familias diversas y los niños LGB a ser representados en el currículo educativo (Corte Suprema de Canadá 20 de diciembre de 2002):

"El primer error de la Junta fue violar los principios de secularismo y tolerancia en s. 76 de la Ley de la Escuela. En lugar de proceder sobre la base del respeto a todos los tipos de familias, el Superintendente y la Junta procedieron con una filosofía de exclusión. Actuaron con base a la preocupación de ciertos padres sobre la moralidad de las relaciones homosexuales, sin considerar los intereses de las familias de padres homosexuales, y de los niños que pertenecen a las mismas, en recibir igual reconocimiento y respeto por el sistema escolar. La Junta no estaba permitida de rechazar los libros simplemente porque ciertos padres encontraron la relación reflejada en ellos controversial u objetable".

En Perú, la Corte Suprema se pronunció al respecto en relación al Currículo Educativo. En términos generales, hubo tantos criterios como magistrados. Hubo quienes dieron primacía a la autonomía de los padres. Por ejemplo, los magistrados Walde Jáuregui y Sánchez Melgarejo señalaron que el Currículo no era idóneo ni necesario, por no haberse probado los efectos beneficiosos del mismo, ni era proporcional a la afectación que sufrían los padres (Corte Suprema, 2019).

Entre quienes de forma correcta dieron primacía a la política educativa del Estado también hubo posiciones partidas. Así, hubo quienes interpretaron bajo un sistema de reglas que los padres en ningún caso podían evitar que se brinde educación sobre derechos fundamentales a sus hijos. Por ejemplo, el magistrado Wong Abad señaló: "Sin embargo, como hemos advertido esta potestad de los 
Educación LGB+. El derecho fundamental a educación básica contra la discriminación por orientación sexual

LGB+ Education. The fundamental right to a basic education against discrimination based on sexual orientation

padres no puede ser entendida como una posibilidad para educar a sus hijos en valores contrarios a la Constitución. Un padre de familia, una entidad educativa de cualquier clase, no pueden exigir, por ejemplo, continuar enseñando la existencia de roles pre-asignados a hombres y mujeres, por razón de su sexo, por cuanto, tal postura, por todo lo explicado resulta inconstitucional" (Corte Suprema, 2019).

Hubo además quienes interpretaron bajo un sistema de principios que en base a un test de ponderación debía primar la política educativa del Estado. Por ejemplo, el magistrado Bustamante Zegarra señaló sin mayor profundización que la medida era proporcional porque "La violencia de género constituye un problema social serio, que exige profundos cambios en la educación, para que, a través de ella, se inculquen a los alumnos nuevas escalas de valores que se construyan sobre el respeto de los derechos fundamentales de todas las personas sin distinción alguna" (Corte Suprema, 2019).

Este caso se trata de un claro ejemplo de una decisión difícil. La discrecionalidad de los padres se funda en los principios de neutralidad y pluralismo del Estado, fundamentales para mantener una sociedad libre. Desde un punto de vista de teoría política, el principio de neutralidad está intrínsecamente ligado con el liberalismo y establece que el Estado no se encuentra legitimado para dictar o imponer a los ciudadanos una u otra forma de vida buena, lo cual sería incurrir en perfeccionismo. Por el contrario, el Estado únicamente puede servir de marco en el cual cada persona debe decidir los valores que considera adecuados para sí mismos (Kymlicka, 2002, pág. 219-220).

Luego, el principio de pluralismo, establece la necesidad de proteger la existencia de diferentes formas de vida y valoraciones dentro de la sociedad. Dicho ideal se encuentra ligado al principio de neutralidad, pero es completamente consistente con el mismo. En ciertos casos, la defensa del pluralismo podría atentar contra la neutralidad del Estado y viceversa (Kymlicka, 2002, pág. 234-235).

Ahora bien, según indica Rawls (2005), la neutralidad y el pluralismo pueden autoanularse en ciertos supuestos. Así, puede darse el caso que ciertas valoraciones y formas de vida sean hostiles a otras formas de vida y tengan como principio atentar contra el resto. En tal sentido, con el objeto de evitarlo, se justifica la intervención del Estado en pro de la tolerancia.

Por otro lado, la educación contra la discriminación es también fundamental para lograr que todos los niños se desarrollen como adultos autónomos. Para tomar la decisión es necesario ponderar la idoneidad, necesidad y proporcionalidad de la limitación a uno de ellos ante la inminente colisión. Consideramos que, en principio, la grave afectación a las vidas de los niños LGB hace necesario limitar la potestad de los padres. La afectación a los principios de neutralidad y pluralismo estatal es leve porque solo se ve limitado un aspecto, entre muchos, de la creencia religiosa o moral: el de la diversidad sexual. Sin embargo, este examen requiere de un análisis caso por caso.

Un proceso educativo ejecutado en abierta contradicción con todos los padres tampoco es un proceso educativo de calidad. En este aspecto entrarían en juego las posibilidades fácticas de implementación del derecho y el propio estándar de adecuación de la educación. Ello involucraría la necesidad de que el Estado busque medidas menos frontales y menos impositivas de lograr la implementación del principio, e.g., llevar a cabo consultas, talleres y capacitación de los padres en la necesidad de incorporar un currículo inclusivo. El Estado debe buscar conciliar con los padres en la búsqueda de la educación inclusiva.

\section{Conclusiones}

En el presente trabajo, se ha demostrado lo siguiente:

a) La diversidad de orientación sexual se manifiesta en los niños desde temprana edad, sea desde manifestaciones de género disidentes o mediante directa atracción sexual, desde la pubertad, a personas del mismo sexo. La orientación sexual diversa es una variación normal del ser humano que no representa un impedimento al normal desarrollo en la sociedad.

b) Es debido a la homofobia imperante en la sociedad e incluso en la escuela, las personas no-heterosexuales y los niños sufren diversos impedimentos en el goce de sus libertades fundamentales, incluyendo graves afectaciones a la salud mental y física, así como la frustración de los proyectos educativos y profesionales.

c) El derecho a la igualdad protege a toda persona y en todo contexto de que se produzcan diferenciaciones en razón de la orientación sexual, incluso disfrazadas de tratos igualitarios. El derecho a la igualdad busca revertir también las situaciones de discriminación estructural como la orientación sexual. Así, una educación que no aborda ni busca 
erradicar la discriminación por orientación sexual, así sea igualitaria para todos los niños independientemente de su orientación sexual, termina siendo discriminatoria y debe ser reformada.

d) El derecho a la educación sustenta también la necesidad de que la educación proteja activamente a los niños LGB de la discriminación. Es un mandato que la educación busque la autonomía de los niños no-heterosexuales, es un mandato que la educación enseñe a todos sobre el derecho a la igualdad y no-discriminación por orientación sexual, es un mandato que la educación sea de calidad también para los niños LGB y es un mandato que la educación se adapte a las necesidades de estos niños.

e) Para ello, desde el Estado, se debe empoderar a los propios alumnos para organizarse, generar un currículo inclusivo, capacitar a los maestros y generar políticas educativas para evitar la discriminación en las aulas y patios. Ello es una necesidad para evitar que siga habiendo niños LGB infelices que maduren en adultos LGB infelices.

f) Finalmente, las valoraciones y estilos de vida particulares de cada familia no justifican limitar este derecho. Todos los niños tienen derecho a comprender y respetar su identidad sexual y la identidad sexual de los demás para lograr una sociedad tolerante y verdaderamente justa.

La educación sirve para ayudarnos a ser libres. Y el amor y el deseo son parte de nuestra libertad, sin importar el género.

\section{Referencias bibliográficas}

Acción de inconstitucionalidad 2/2010 (Suprema Corte Nacional de Justicia [México], 16 de agosto de 2010).

A.D.T. vs. United Kingdom, 35765/97 (Tribunal Europeo de Derechos Humanos, 31 de julio de 2000).

Alexy, R. (1989). A theory of legal argumentation. The theory of rational discourse as theory of legal justification. Oxford: Oxford University Press.

Alexy, R. (1993). Teoría de los derechos fundamentales. Madrid: Centro de Estudios Constitucionales.

Alexy, R. (2006). Discourse theory and fundamental rights. En A. Menéndez \& E. Oddvar Eriksen. Arguing fundamental rights. Dordrecht: Springer.

Alto Comisionado de las Naciones Unidas para los Derechos Humanos (2015). Discriminación y violencia contra las personas por motivos de orientación sexual e identidad de género. Informe del Alto Comisionado de las Naciones Unidas para los Derechos Humanos. (Documento No. A/HRC/29/23).

American Association of University Women (2004). How Schools Shortchange Girls: Three Perspectives on Curriculum. En D. Flinders \& S. Thornton (edit.), The curriculum studies reader. New York: Routledge Falmer.
American Psychological Association (2012). Guidelines for Psychological Practice with Lesbian, Gay, and Bisexual Clients. American Psychologist, 67(1), pág. 10-42.

(2015). School-Based Risk and Protective Factors for Gender Diverse and Sexual Minority Children and Youth. Improving School Climate.

Atala Riffo e hijas vs. Chile (Corte Interamericana de Derechos Humanos, 24 de febrero de 2012).

Bamforth, N. (1997). Sexuality, morals and justice. A theory of lesbian and gay rights law. Londres y Washington: Cassell.

Banks, J. (2013). Multicultural education: Characteristics and goals. En J. Banks \& C. McGee Banks (edit.). Multicultural education. Issues and perspectives (8va ed.). New Jersey: Wiley.

Beiter, K. D. (2006). The protection of the right to education by international law. Including a systematic analysis of Article 13 of the International Covenant on Economic, Social, and Cultural Rights. Leiden: Martinus Nijhoff.

Biegel, S. \& Kuehl, S. (2010). Safe at school: Addressing the School Environment and LGBT Safety through Policy and Legislation. Williams Institute in the UCLA Law School, the National Education Policy Center (NEPC).

Bowers vs. Hardwick, 478 U. S. 186 (1986) (Corte Suprema [Estados Unidos], 31 de marzo de 1986).

Brown et al. vs. Board of Education of Topeka, 447 U.S. 4831953 (Corte Suprema [Estados Unidos], 17 de mayo de 1954).

Bullard, A. (2018). Efectivamente: con mis hijos no te metas. Perú 21. Recuperado el 13 de mayo de 2019, de https://peru21.pe/opinion/efectivamentemis-hijos-metas-441090

Butler, J. (1990). Gender trouble: feminism and the subversion of identity. New York: Routledge.

B. vs. France, 232-C (Tribunal Europeo de Derechos Humanos, 25 de marzo de 1992).

Cáceres, C F. et al. (2013). "Era como ir todos los días al matadero...": El bullying homofóbico en instituciones públicas de Chile, Guatemala y Perú. Documento de trabajo. Lima: IESSDEH, UPCH, PNUD, UNESCO.

Callan, E. (1997). Creating citizens. Political education and liberal democracy. Oxford: Clarendon Press.

Calzo, J. et al. (2011). Retrospective Recall of Sexual Orientation Identity Development Among Gay, Lesbian, and Bisexual Adults. Developmental Psychology, 47(6), pág. 1658-1673. 
Educación LGB+. El derecho fundamental a educación básica contra la discriminación por orientación sexual

LGB+ Education. The fundamental right to a basic education against discrimination based on sexual orientation

Carole Louise Webb vs EMO Air Cargo (UK) Ltd.ECLI:EU:C:1994:300 (Tribunal Europeo de Justicia, 14 de julio de 1994).

Case of Campbell and Cosans vs. The United Kingdom, 7511/76; 7743/76 (Tribunal Europeo de Derechos Humanos, 25 de febrero de 1982).

Case "Relating to certain aspects of the laws on the use of languages in education in Belgium" vs. Belgium (Merits), 1474/62; 1677/62; 1691/62; 1769/63; 1994/63; 2126/64 (Tribunal Europeo de Derechos Humanos, 23 de julio de 1968).

Case of Valsamis vs. Greece, $21787 / 93$ (Tribunal Europeo de Derechos Humanos, 18 de diciembre de 1996).

Caso Salgueiro da Silva Mouta v. Portugal (Tribunal Europeo de Derechos Humanos, 21 de diciembre de 1999).

Cecilia Derksen vs. The Netherlands, 976/2001 (Comité de Derechos Humanos de las Naciones Unidas, 01de abril de 2004).

Centre for the Legal Protection of Human Rights (INTERIGHTS) vs. Croatia, (2009)7 (Comité de Ministros del Consejo de Europa, 21 de octubre de 2009).

Chamberlain vs School District No. 36, SCC 86 (Corte Suprema [Canadá], 20 de diciembre de 2002).

Christine Goodwin vs. Reino Unido, 28957/95 (Tribunal Europeo de Derechos Humanos, 11 de julio de 2002).

Cochran, S. (2001). Emerging issues in research on lesbians' and gay men's mental health: Does sexual orientation really matter? American Psychologist, 56(1), pág.931-947.

Colegio de abogados del Cusco y del Callao y más de cinco mil ciudadanos c/. Congreso de la República (Tribunal Constitucional [Perú], 3 de junio de 2005).

Collins, J. (2009). Social reproduction in classrooms and schools. Annual review of anthropology, 38, pág. 3-48.

Colom Cañellas, A. (ed.) (1997). Teorías e instituciones contemporáneas de la educación. Barcelona: Ariel Educación.

Comisión Interamericana de Derechos Humanos (2012). Orientación sexual, identidad de género y expresión de género: algunos términos y estándares relevantes. (Documento No. CP/CAJP/INF. 166/12).

Comisión Interamericana de Derechos Humanos (2015). Violencia contra Personas Lesbianas, Gays, Bisexuales, Trans e Intersex en América. Comisión Interamericana de Derechos Humanos.

Comité de Derechos Económicos, Sociales y Culturales (1990). Aplicación del Pacto Internacional de los Derechos Económicos, Sociales y Culturales, Observación general 13, El derecho a la educación (artículo 13 del Pacto), (210 período de sesiones, 1999). U.N. Doc. E/C.12/1999/10.

Comité de los Derechos del Niño de Naciones Unidas (2003). General comment No. 4 (2003): Adolescent Health and Development in the Context of the Convention on the Rights of the Child, CRC/GC/2003/4. Recuperado el 31 de marzo de 2018, de http://www.refworld.org/ docid/4538834f0.html

Connors vs. The United Kingdom, 66746/01 (Tribunal Europeo de Derechos Humanos, 27 de agosto de 2004).
Cotino Hueso, L. (2012). El derecho a la educación. En: G. Escobar (direct.), Derechos sociales y tutela antidiscriminatoria. Navarra: Aranzandi.

D’Augelli, A. (1994). Identity development and sexual orientation: Toward a model of lesbian, gay, and bisexual development. En E. Trickett et al (ed.). Human diversity: perspectives in context. San Francisco: Josey Bass.

Dawood, K.; Bailey, M. \& Martin, N. (2009). Genetic and environmental influences on sexual orientation. En Yong-Kyu Kim (ed.), Handbook of behavior genetics. New York: Springer.

D.H. et al vs. The Czech Republic, 57325/00 (Tribunal Europeo de Derechos Humanos, 13 de noviembre de 2007).

Diamond, L. (2003). What does sexual orientation orient? A biobehavioral model distinguishing romantic love and sexual desire. Psychological review, 110(1), pág. 173-192.

Drescher, J. (2015). Out of the DSM: Dephatologyzing homosexuality. Behavioral sciences, 5(4), pág. 565-575.

Dudgeon vs. El Reino Unido, 7525/76 (Tribunal Europeo de Derechos Humanos, 22 de octubre de 1981).

Dworkin, R. (2011). Justice for hedgehogs. Cambridge: The Belknap Press of Harvard University Press.

E.B. vs. Francia, 43546/02 (Tribunal Europeo de Derechos Humanos, 22 de enero de 2008).

Edward Young vs. Australia, 941/2000 (Comité de Derechos Humanos de las Naciones Unidas, 06 de agosto de 2003).

Eguiguren Praeli, F. (1997). Principio de igualdad y derecho a la no discriminación. Ius et veritas, 15, pág. 63-72.

Elisabeth Johanna Pacifica Dekker vs. Stichting Vormingscentrum voor Jong Volwassenen (VJVCentrum) Plus, C-177/88 [1991] IRLR 27 (Tribunal Europeo de Justicia, 8 de noviembre de 1990).

Expediente No. 22863-2012-0-1801-JR-Cl-08 (Corte Superior de Justicia de Lima. Cuarta Sala Civil [Perú], 19 de enero de 2018).

Expediente 23822-2017 (Corte Suprema [Perú], 06 de marzo de 2018).

Expediente 0011-2002-Al (Tribunal Constitucional [Perú], 10 de junio de 2002).

Expediente 0964-2002-AA/TC (Tribunal Constitucional [Perú], 17 de marzo de 2003).

Expediente 0261-2003-AA/TC (Tribunal Constitucional [Perú], 26 de marzo de 2003). 
Expediente 1013-2003-HC/TC (Tribunal Constitucional [Perú], 30 de junio de 2003).

Expediente 0008-2003-AI/TC (Tribunal Constitucional [Perú], 16 de julio de 2003).

Expediente 2016-2004-AA/TC (Tribunal Constitucional [Perú], 29 de enero de 2004)

Expediente 0858-2003-AA/TC (Tribunal Constitucional [Perú], 24 de marzo de 2004).

Expediente 0606-2004-AA/TC (Tribunal Constitucional [Perú], 28 de junio de 2004).

Expediente 2945-2003-AA (Tribunal Constitucional [Perú], 20 de abril de 2004).

Expediente 03869-2012-PA/TC (Tribunal Constitucional [Perú], 6 de agosto de 2004)

Expediente 0091-2005-PA/TC (Tribunal Constitucional [Perú], 18 de febrero de 2005).

Expediente 4232-2004-AA/TC (Tribunal Constitucional [Perú], 3 de marzo de 2005)

Expediente 0048-2004-PI/TC (Tribunal Constitucional [Perú], 1 de abril de 2005).

Expediente 00053-2004-PI/TC (Tribunal Constitucional [Perú], 16 de mayo de 2005).

Expediente 1417-2005-PA/TC (Tribunal Constitucional [Perú], 8 de julio de 2005)

Expediente 5854-2005-PA/TC (Tribunal Constitucional [Perú], 8 de noviembre de 2005).

Expediente 0030-2005-PI/TC (Tribunal Constitucional [Perú],2 de febrero de 2006).

Expediente 1209-2006-PA/TC (Tribunal Constitucional [Perú], 14 de abril de 2006).

Expediente 2273-2005-PHC/TC (Tribunal Constitucional [Perú], 20 de abril de 2006).

Expediente 5033-2006-PA/TC (Tribunal Constitucional [Perú], 29 de agosto de 2006).

Expediente 2192-2004-AA /TC (Tribunal Constitucional [Perú], 11 de octubre de 2006).

Expediente 04646-2007-PA/TC (Tribunal Constitucional [Perú], 17 de octubre de 2007).

Expediente 02370-2007-PA/TC (Tribunal Constitucional [Perú], 7 de noviembre de 2007).

Expediente 01407-2007-PA/TC (Tribunal Constitucional [Perú], 8 de agosto de 2008).

Expediente 05652-2007-PA/TC (Tribunal Constitucional [Perú], 6 de noviembre de 2008).

Expediente 05527-2008-PHC/TC (Tribunal Constitucional [Perú], 11 de febrero de 2009).

Expediente 00002-2008-PI/TC (Tribunal Constitucional [Perú], 9 de setiembre de 2009).
Expediente 03052-2009-PA/TC (Tribunal Constitucional [Perú], 14 de julio de 2010).

Expediente 01151-2010-PA/TC (Tribunal Constitucional [Perú], 30 de noviembre de 2010).

Expediente 03660-2010-PHC/TC (Tribunal Constitucional [Perú], 25 de enero de 2011).

Expediente 03850-2011-PA/TC (Tribunal Constitucional [Perú], 24 de octubre de 2011).

Expediente 02835-2010-PA/TC (Tribunal Constitucional [Perú], 13 de diciembre de 2011).

Expediente $01392013-P A / T C$ (Tribunal Constitucional [Perú], 18 de marzo de 2014).

Expediente 1423 -2013 -PA/TC (Tribunal Constitucional [Perú], 9 de diciembre de 2015).

Expediente 06040-2015-PA/TC (Tribunal Constitucional [Perú], 21 de octubre de 2016).

Fausto-Sterling, A. (1993). The five sexes. Why male and female are not enough. The Sciences, 33(2), pág. 20-24

Fausto-Sterling, A. (2000). Sexing the body. Gender politics and the construction of sexuality. New York: Basic books.

Floyd, F. \& T. Stein (2002). Sexual Orientation Identity Formation among Gay, Lesbian, and Bisexual Youths: Multiple Patterns of Milestone Experiences. Journal of research on adolescence, 12(2), pág. 167-191. https://doi.org/10.1111/15327795.00030

Formby, E. (2016). Sexuality education with LGBT young people. En J. Ponzetti (edit.), Evidencebased approaches to sexuality education. New York: Routledge.

Folgerø vs. Norway, 15472/02 (Tribunal Europeo de Derechos Humanos, 29 de junio de 2007).

Foucault, M. (2012). Historia de la sexualidad: el uso de los placeres. Buenos Aires: Siglo XXI.

Frans, E. (2016). A practical guide to holistic sexuality education. En: Ponzetti, James (ed.). "Evidence-based approaches to sexuality education." New York: Routledge.

Fredman, S. (2011). Discrimination law. New York: Oxford University Press.

Gavara de Cava, J. (2005). Contenido y función del término de comparación en la aplicación del principio de igualdad. Navarra: Aranzandi.

Gaygusuz vs. Austria, 17371/90 (Tribunal Europeo de Derechos Humanos, 16 de setiembre de 1996).

Gemma Beasley vs. Australia, 11/2013 (Committee on the Rights of Persons with Disabilities. 1 de abril de 2016) 
Educación LGB+. El derecho fundamental a educación básica contra la discriminación por orientación sexual

LGB+ Education. The fundamental right to a basic education against discrimination based on sexual orientation

Grant vs. Reino Unido, 32570/03 (Tribunal Europeo de Derechos Humanos, 23 de mayo de 2006).

Griggs vs. Duke Power Co (Corte Suprema [Estados Unidos], 8 de marzo de 1971).

Gutmann, A. (1987). Democratic education. New Jersey: Princeton.

Hatzenbuehler, M. (2009). How does sexual minority stigma "get under the skin"? A psychological mediation framework. Psychological bulletin, 135(5), pág. 707-730.

Herdt, Gilbert H. (1981). Guardians of the Flutes: Idioms of Masculinity. New York: McGraw-Hill.

Hernández Guanche, V. (2009). Intersexualidad y prácticas científicas: ¿ciencia o ficción? Revista de investigaciones políticas y sociológicas, 8(1), pág. 89-102.

International Commission of Jurists (2007). Los Principios de Yogyakarta: Principios sobre la aplicación de la legislación internacional de derechos humanos en relación con la orientación sexual y la identidad de género.

Jane Margarita Cósar Camacho y otros, expediente No. 02437-2013PA/TC (Tribunal Constitucional [Perú], 16 de abril de 2014).

Juliet Joslin et al. vs. New Zealand, 902/1999 (Comité de Derechos Humanos de las Naciones Unidas, 30 de julio de 2002).

Ketting, Evert et al. (2015). Evaluation of holistic sexuality education: A European expert group consensus agreement. The European Journal of Contraception and Reproductive Health Care, 21(1), 1-13. 10.3109/13625187.2015.1050715

Kymlicka, W. (2002). Contemporary political philosophy. An introduction. (2da ed.). New York: Oxford University Press.

Kinsey, Alfred et al. (1993). Sexual Behavior in the human female. En W. Rubenstein, Lesbians, Gay men and the Law. New York: The New Press.

Kinsey, Alfred et al. (1993). Sexual Behavior in the human male. En W. Rubenstein, Lesbians, Gay men and the Law. New York: The New Press.

Kjeldsen, Busk Madsen and Pedersen vs. Denmark, 5095/71; 5920/72; 5926/72 (Tribunal Europeo de Derechos Humanos, 7 de diciembre de 1976).

Kozak vs. Polonia, 13102/02 (Tribunal Europeo de Derechos Humanos, 2 de junio de 2010).

Kosciw, J.G., Greytak, E. A., Palmer, N. A., y Boesen, M. J. (2014). The 2013 National School Climate Survey: The experiences of lesbian, gay, bisexual and transgender youth in our nation's schools. New York: GLSEN.

Kosciw, Joseph G.; Emily A. Greytak; Noreen M. Giga; Christian Villenas \& David J. Danischewski. (2016). The 2015 National School Climate Survey The Experiences of Lesbian, Gay, Bisexual, Transgender, and Queer Youth in Our Nation's Schools. New York: GLSEN.

Lawrence vs. Texas, 539 U. S. 558 (2003) (Corte Suprema [Estados Unidos], 26 de junio de 2003).

Levinson, Meira. (2004). The demands of liberal education. New York: Oxford University Press.

Levy, Sheri et al. (2016). Understanding and reducing racial and ethnic prejudice among children and adolescents. En T. Nelson (edit.), Handbook of prejudice, stereotyping and discrimination (2da ed.). New York: Psychology Press.

Ley de Reforma Magisterial 2, expediente No. 0020-2012-P1/TC (Tribunal Constitucional [Perú], 16 de abril de 2014).

Liliane Gröninger vs. Alemania, 2/2010 (Committee on the Rights of Persons with Disabilities. 4 de abril de 2014).

L. vs. Lituania, 27527/03 (Tribunal Europeo de Derechos Humanos, 11 de septiembre de 2007).

Marquez, N. y A. Laje (2016). El Libro Negro de la Nueva Izquierda: Ideología de género o subversión cultural. Buenos Aires: Grupo Unión.

Mayo, C. (2013). Queer lessons: sexual and gender minorities in multicultural education. En J. Banks \& C. McGee Banks (ed.). Multicultural education. Issues and perspectives (8va ed.). New Jersey: Wiley.

McCrudden, C. \& S. Prechal (2009). The conceptos of equality and non-discrimination in Europe: a practical approach. European Network of Legal Experts in the Field of Gender Equality.

McGarry, R. (2013). Build a curriculum that includes them all. Kappan Magazine, 94(5), pág. 66-71.

Meix Cereceda, P. (2014). El derecho a la educación en el sistema internacional y europeo. Valencia: Tirant lo Blanch.

Meyer, E. (2010). Gender and sexual diversity in schools. NewYork: Springer.

Modinos vs. Cyprus, 15070/89 (Tribunal Europeo de Derechos Humanos, 22 de abril de 1993.).

Moschella, M. (2016). To whom do children belong. Parental rights, children education, and children autonomy. New York: Cambridge University Press.

Norris vs. Ireland, 10581/83 (Tribunal Europeo de Derechos Humanos, 26 de octubre de 1988).

Obergefell et al. vs. Hodges et al., 576 U. S (2015) (Corte Suprema [Estados Unidos], 26 de junio de 2015).

Oliari et al. vs. Italia, 18766/11 y 36030/11 (Tribunal Europeo de Derechos Humanos, 21 de julio de 2015).

Óscar Ugarteche Galarza. Resolución No. 13 (Sétimo Juzgado Constitucional de Lima [Perú], 21 de diciembre de 2016).

Palmer, N et al. (2017). Dirupting hetero-gendernormativity. The complex role of LGBT affirmative supports at school. En S. Russell \& Stacey Horn, Sexual orientation, gender identity, and schooling. The nexus of research, practice and policy. New York: Oxford University Press. 
Perez-Wicht Arispe, J. (2017). Identidad sexual y satisfacción de pareja en hombres homosexuales de Lima Metropolitana. (Tesis para optar por el título de Licenciado en Psicología). Pontificia Universidad Católica del Perú. Recuperado el 4 de marzo de 2018, de http:// tesis.pucp.edu.pe/repositorio/bitstream/handle/123456789/9832/ Perez-Witch\%20Arispe_Identidad_sexual_satisfacci\%C3\%B3n1. pdf? sequence=1\&isAllowed $=y$

Pettigrew, T. (1998). Intergroup contact theory. Annual Review of Psychology, 49(1), pág. 65-85.

Poteat, P. (2017). Understanding and reducing homophobic harassment and victimization in schools. En S. Russell \& Stacey Horn, Sexual orientation, gender identity, and schooling. The nexus of research, practice and policy. New York: Oxford University Press.

PROMSEX (2016). Estudio Nacional sobre Clima Escolar en el Perú 2016. Lima: PROMSEX.

Rahman, Q \& G. D. Wilson. (2013). Born gay? The psychobiology of sexual orientation. Personality and individual differences, 34(8), pág. 1337-1382.

Rawls, J. (2005). Political liberalism. New York: Columbia University Press.

Relator Especial de las Naciones Unidas sobre el derecho a la educación (2010). Informe del Relator Especial de las Naciones Unidas sobre el derecho a la educación. Documento No. A/65/162.

Rey Martínez, F. (2018). Igualdad y prohibición de discriminación: de 1978 a 2018. Revista de Derecho político, 100, pág 125-171.

Rey, Augusto. (2018). ¿Tiranía educativa? Perú 21. Recuperado el 13 de mayo de 2019, de https://peru21. pe/opinion/tirania-educativa-441682.

Rivers, I. (1997). Lesbian, Gay and Bisexual Development: Theory, Research and Social Issues. Journal of Community \& Applied Social Psychology, 7 (5).

Roberts, Andrea et al. (2010). Pervasive trauma exposure among US sexual orientation minority adults and risk of posttraumatic stress disorder. American journal of public health, 100(12), pág. 2433-2441.

Rubin, G. (1975). The traffic in women: Notes on the "political economy" of sex. En Rayna Reiter (edit.), Toward an Anthropology of Women. New York: Monthly View Press.

Rupert Althammer et al. vs. Austria, 998/2001 (Comité de Derechos Humanos de las Naciones Unidas, 22 de setiembre de 2003).

Sadowski, M. (2016). Safe is not enough. Better schools for LGBTQ students. Cambridge: Harvard University Press.

Sejdić y Finci vs. Bosnia Herzegovina, 27996/06 y 34836/06 (Tribunal Europeo de Derechos Humanos, 22 de diciembre de 2009).

Sentencia SU214/16 (Corte Constitucional [Colombia], 28 de abril de 2016).

Sentencia T-478/15 (Corte Constitucional [Colombia], 03 de agosto de 2015).

Shapiro, D. (2007). Is the welfare state justified? Cambridge: Cambridge University Press.

Sidabras y Džiautas vs. Lituania, 55480/00 y 59330/00 (Tribunal Europeo de Derechos Humanos, 27 de julio de 2004).
Simunek et al. vs. The Czech Republic, 516/1992 (Comité de Derechos Humanos de las Naciones Unidas, 31 de julio de 1995.

Snapp, S. \& S. Russell (2017). Inextricably linked. The shared story of ethnic studies and LGBTQinclusive curriculum. En S. Russell \& Stacey Horn, Sexual orientation, gender identity, and schooling. The nexus of research, practice and policy. New York: Oxford University Press.

Spitzer, R. (2003). Can some gay men and lesbians change their sexual orientation? 200 participants reporting a change from homosexual to heterosexual orientation. Archives of sexual behavior, 32(5), pág. 403-417.

Stabback, P. (2016). What makes a quality curriculum? Ginebra: UNESCO International Bureau of Education

Style, E. (1988). Curriculum as window and mirror. En Oak Knoll School monograph Listening for All Voices Summit" New Jersey. Recuperado de http://webapp1.dlib.indiana.edu/virtual disk_library/index.cgi/4273355/FID840/eqtyres/ erg/111548/1548.htm

Thornton, S. (2004). Silence on gays and lesbians in social studies curriculum. En D. Flinders \& Stephen Thornton (edit.), The curriculum studies reader. New York: Routledge Falmer.

Toonen vs. Australia, 488/1992 (Comité de Derechos Humanos de las Naciones Unidas, 31 de marzo de 1994).

UNESCO (2013). Respuestas del sector de educación frente al bullying homofóbico. Cuadernillo No. 8. Santiago de Chile: UNESCO, 2013; pág. 22-25. Recuperado el 1 de abril de 2017, de http://unesdoc.unesco.org/ images/0022/002229/222918S.pdf

UNESCO (1974). Recomendación sobre la educación para la comprensión, la cooperación y la paz internacionales y la educación relativa a los derechos humanos y las libertades fundamentales aprobada por la Conferencia General en su decimoctava reunión. París, 19 de noviembre de 1974.

UNESCO (2013). Respuestas del sector de educación frente al bullying homofóbico. Cuadernillo No. 8. Santiago de Chile: UNESCO. Recuperado el 1 de abril de 2017, de http://unesdoc. unesco.org/images/0022/002229/222918S.pdf

UNESCO (2014). Teaching respect for all. Implementation guide. Paris: UNESCO.

UNESCO (2015). El bullying homofóbico y transfóbico en los centros educativos. Taller de sensibilización para su prevención. Guía de facilitación. Santiago de Chile: UNESCO. 
Educación LGB+. El derecho fundamental a educación básica contra la discriminación por orientación sexual

LGB+ Education. The fundamental right to a basic education against discrimination based on sexual orientation

UNESCO (2015). La violencia homofóbica y transfóbica en el ámbito escolar: hacia centros educativos inclusivos y seguros en América Latina. Santiago de Chile: UNESCO.

UNESCO (2016). Out in the open. Education sector responses to violence based on sexual orientation and gender identity/expression. Paris: UNESCO.

Vallianatos et al. vs. Grecia, 29381/09 and 32684/09 (Tribunal Europeo de Derechos Humanos, 7 de noviembre de 2013).

Van Kück vs. Germany, 35968/97 (Tribunal Europeo de Derechos Humanos, 12 de junio de 2003).
Weller vs. Hungría, 44399/05 (Tribunal Europeo de Derechos Humanos, 31 de marzo de 2009).

World Conference on Education for All. 1990. World declaration on education for all. Meeting basic learning needs. Tailandia.

Zizek, S. 2012 [1989]. El sublime objeto de la ideología. Siglo XXI.

Zucker, Ket al. (2008). A Follow-Up Study of Girls With Gender Identity Disorder. Developmental Psychology, 44(1), pág. 34-45.

Zucker, K. (2003). The politics and science of "reparative therapy". Archives of sexual behavior, 32(5), pág. 399-402.

Zwaan de Vries vs. The Netherlands, 182/1984 (Comité de Derechos Humanos de las Naciones Unidas, 28 de setiembre de 1984).

\section{Rebaza, Alcázan \& De Las Casas}

Fusiones y Adquisiciones

Reestructuración y Quiebras

Financiamientos

Mercado de Capitales

Proyectos e Infraestructura

Inversión Exranjera

Asesoría Corporativa

Planificación Tributaria
Planificación Laboral

White Collar Crime

Litigios Corporativos

Arbitraje

Private Clients

Venture Capital

Compliance

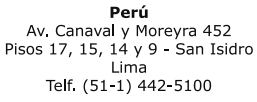
Oficina de representación quindo 3600 Piso 5 - Las Santiago de Chile
Telf. (56-2) 2244-68432

www.rebaza-alcazar.com 